\title{
Experimental Measurement of the Nearfield Longitudinal Wake Profiles of a High-Speed Prismatic Planing Hull
}

\author{
Angus Gray-Stephens \\ Department of Naval \\ Architecture, Ocean \& Marine \\ Engineering \\ The University of Strathclyde \\ Glasgow, Scotland, UK
}

\author{
Tahsin Tezdogan \\ Department of Naval \\ Architecture, Ocean \& Marine \\ Engineering \\ The University of Strathclyde \\ Glasgow, Scotland, UK
}

\author{
Sandy Day \\ Department of Naval \\ Architecture, Ocean \& Marine \\ Engineering \\ The University of Strathclyde \\ Glasgow, Scotland, UK
}

\section{ABSTRACT}

This study details an extensive investigation into the nearfield longitudinal wake profiles of a high-speed planing hull. Developing a more thorough understanding of the flow in this region is of benefit to the designers of stepped hulls, who are required to determine how the forebody's wake will intersect with the afterbody. As no experimental data was available within the public domain, a novel small-scale model-testing program was undertaken, measuring Centreline (CL) and Quarter Beam (QB) nearfield longitudinal wake profiles, as well as the resistance, lift and trimming moment of a prismatic hull. The nearfield wake profile was found to exhibit trends in agreement with the findings of previous work investigating the mid and far field wake patterns. The results of this experimental work are provided in full as validation data. Two methods of modelling these profiles, Savitsky's Wake Equations and the Linear Wake Assumption are then assessed to determine the level of confidence with which they may be used. It was found that Savitsky's Wake Equations displayed a surprising level of accuracy whereas the Linear Wake Assumption was not valid for the conditions investigated. 


\section{INTRODUCTION}

The design and production of planing craft has been commonplace for several decades now. Despite this there is a notable gap between the knowledge on the subject held by industry, and the available academic work. Lessons and practices developed commercially are often treated as confidential and are only available to the company who developed them. In cases where companies are willing to share results, little effort is made to disseminate findings to the wider academic community. This makes sense in a competitive market where companies are striving to stand out and sharing information may give away some possible advantage. In academia there has been a steady progression in the available work researching high-speed hulls over the years.

An alternative hull configuration to the standard planing hull is the stepped planing hull. This allows a substantial decrease in the hydrodynamic resistance of a hull over its non-stepped equivalent at high speeds. To achieve this, the hull is divided into a number of joined planing surfaces at progressively raised elevations. Behind each of these steps the flow separates, reducing the wetted surface area. The hull is essentially turned from one lowaspect planing surface into a number of joined higher-aspect surfaces, allowing the same amount of lift to be generated with a reduction in drag.

When a stepped hull is employed, any method of performance prediction must calculate the forces and moments acting on each section of the hull, before summing them to solve for the global forces and moments that establish the total resistance, lift and the equilibrium position of the hull. To determine the forces acting upon each of the lifting surfaces, both the wetted area and the relative deadrise angle between the fluid surface and the hull must be known. In order to calculate these, it is vital to be able to accurately model the wake pattern associated with the forebody flow so that how it intersects with the afterbody may be determined. Errors introduced through the incorrect modelling of this wake pattern may result in large differences in the wetted area and relative deadrise, leading to the incorrect calculation of forces and moments acting upon each surface. While the calculation of resistance is negatively affected, it is the calculation of the hulls equilibrium position that suffers the greatest accuracy loss when this happens. This is due to the incorrect distribution of forces and moments arising from the incorrect wetted area and relative deadrise calculations.

For these reasons, establishing a method of reliably and accurately modelling the nearfield wake is crucial to the performance prediction and design of stepped planning hulls. To this end, Savitsky performed an extensive model-testing program in 2010, measuring the wake profiles of prismatic planing hulls in a number of test conditions (Savitsky and Morabito, 2010). The data was used to develop empirical formulae that calculate the longitudinal wake profile at the Centreline (CL) and the Quarter Beam (QB) longitudinals of a planing hull, given that it fits within certain parameters. To date, Savitsky's work is the only example of an in-depth investigation into the nearfield wake of planing hulls that looks to capture or model the longitudinal wake profile directly aft of the hull.

The study reported in this paper aims to provide further insight into the behaviour of the wake profile in this region. The experimental results were also used to justify the abilities of Savitsky's Wake Equations and the Linear Wake Assumption in modelling the nearfield longitudinal wake profile. Modelling the wake profiles without the presence of the afterbody changes the physics of the problem and simplifies it massively, however, this still provides a good validation case for the capabilities of these methods when applied to a stepped hull. This simplification was necessary as experimentally extracting the wake profiles behind a step with anything other than photographs of the wetted areas is extremely challenging and is not something that has been achieved by researchers to date. As such, there is no available validation data for cases where the afterbody is included.

Firstly, Savitsky's Empirical Wake Equations were investigated to establish how well they perform when applied to hull conditions that are out with their range of applicability. Following this the simplified Linear Wake Assumption was assessed to determine if it is valid and where its range of applicability lies. No experimental data is available within the public domain, so a novel small-scale model-testing program was undertaken, measuring the Centreline (CL) and Quarter Beam (QB) nearfield longitudinal wake profiles, as well as the resistance, lift and trimming moment. 
The paper begins by presenting an in-depth literature review of previous experimental and analytical studies on the subject. It then goes on to highlight the aims of the work and methodology that was used to achieve these. Each of the methods under investigation is then detailed, with information being presented on the experimental set up. Finally, the results are presented and discussed before the paper is rounded off with the concluding remarks and recommendations for future work.

\section{LITERATURE REVIEW}

There are several examples of experimental studies attempting to extract the wake profiles from planing surfaces, however, these are largely limited to studies on the floats of seaplanes. One of the first examples of these studies was Sottorf (1932), who investigated water-based aircraft and presented several examples of the longitudinal centreline wake profiles. The study was limited to only one speed and displacement for a number of deadrise hulls. Following on from this Korvin-Kroukovsky et al. (1948b, 1948a, 1949) published a number of wake profile plots for a range of conditions. These reports were once again intended for use with seaplane hulls. The summary report questioned the reliability of the data for trim angles less than 6 degrees preventing the use of the data in the design of planing hulls, which typically operate at lower trim angles.

Thornhill et al. (2003) conducted a series of bare hull resistance tests of a planing hull for a range of conditions to provide validation data for Computational Fluid Dynamics (CFD). Measurements were made of the forces, moments, trim, wetted area, pressures and wave profiles. The wave profiles were measured using a transverse array of 23 capacitance probes, the first of which was located 7 inches from the side of the model. A proximity switch was used to correlate the location of the model with the wave probe data. This setup allowed the full wake-field of the hull to be captured, excluding the longitudinal wake profiles directly behind the hull as no data was measured in this region.

A number of other studies have used capacitance probes transversely offset from the path of a towed planing model to measure the mid and far-field wake profiles (Callander, 2015; De Luca and Pensa, 2017). This approach is unsuitable to analyse the nearfield wake profiles as no capacitance probes can be placed in the path of the model.

Callander (2015) went on to use the measured experimental data to evaluate the MacPhail Two-Dimensionalplus-time $(2 \mathrm{D}+\mathrm{t})$ method (MacPhail and Tye, 1944) for application with planing hulls. The authors found it was able to model the amplitude of the primary and secondary waves relatively well for a flat plate, however, was less capable of predicting the locations of the wave peaks. When a V-bottom hull was investigated, the method struggled at calculating both the peak location and the amplitudes. The authors conclude that the MacPhail 2D+t method was able to model the trends of the experimental data but requires modification to improve its accuracy.

In addition to the aforementioned studies examining planing hulls, there have been numerous investigations into High Speed Vessels with transom sterns. Whilst these vessels are not operating in the fully planing regime the techniques employed and findings published are of note. Early work investigating the transom stern was documented by Saunders (1957), who conducted an experimental study proving this to be advantageous due to the decrease in resistance when it is fully ventilated. Doctors (2003) conducted model tests to study the development of the ventilation and the transom wake. He developed a regression equation for modelling the transom wake and thus level of stern ventilation that was implemented to a potential flow solver, greatly improving the resistance prediction. The applicability of this to other vessels is unknown due to the limitations of the experimental study. Fu et al., (2005) conducted what is perhaps the most in depth study of the wake pattern developed by a vessel with a transom stern. A number of methods were employed, with capacitance probes being utilised to measure the mid and far-field wake, and a combination of conductivity finger probes and Quantative Visulisation (QViz) being used to measure the nearfield wake. A comprehensive data set was published, intended for use in the validation of CFD code. Maki et al. (2006) conducted experiments using a five geosim transom stern models. A wave-elevation probe was used to measure the free-surface elevation in a longitudinal cut behind the transom. The focus of this study was once again in attempting to model how and when ventilation of the transom stern occurred.

Savitsky and Morabito (2010) conducted the only investigation into the nearfield wake of a planing hull to date. The aim was to develop empirical equations that quantitatively defined the longitudinal surface wake profiles 
aft of a prismatic planing hull. These equations allow designers of stepped planing hulls to determine how the flow of the forward hull would intersect with the aft hull. Originally, they planned to extract data from existing publications, but after a broad literature review, concluded that none was applicable. Following this, they conducted an extensive experimental test program to provide results. The experimental program measured the wake profile by attaching a thin vertical plate that was marked with a grid to the transom of the models, as seen in Figure 1. Photographs of the plate then allowed the longitudinal wake profile to be extracted, using the grid as a reference. Whilst this presents a simple and fast method of gathering data it is relatively crude and there is no discussion on if and how the presence of the plate affects the wake itself, as the wake comprises of complex 3D flow. The authors use the experimental data to evaluate the developed empirical equations, finding a good agreement between the results. There is a noticeable scatter in the results and it is clear that while an empirical equation may be capable of providing a good representation of the wake profiles they will not be entirely accurate for all cases.

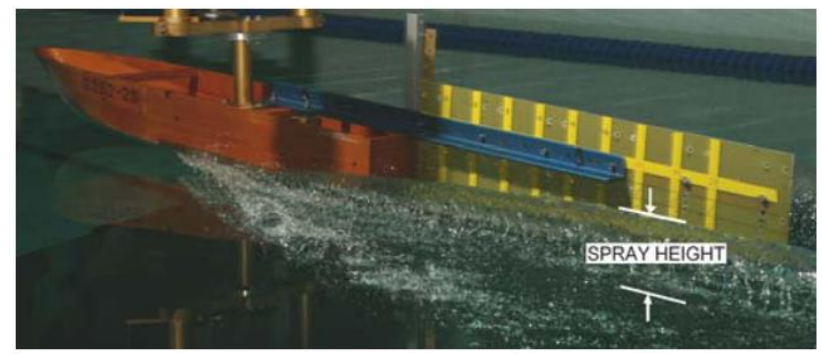

Figure 1 - Experimental set up of (Savitsky and Morabito, 2010)

A number of studies makes use of Savitsky's Wake Equations in conjunction with numerical tools, primarily as one-off validation cases of the CFD (Faison, 2014; Ghadimi et al., 2015). In most cases Savitskys empirical equations are shown to have a reasonable correlation with numerical solution, however, in some cases there is a significant difference. As there is no experimental data for these validation cases, it is unknown which of the methods is closer to the real solution. There are no examples in the literature of studies investigating the accuracy of various methods of calculating the nearfield longitudinal wake profile of a planing hull.

The only example of an experimental study researching the topic was Savitsky and Morabito (2010), who only published the developed empirical equations rather than publishing individual test results. Whilst these allow a rudimentary validation of a simulation, the scatter that was present between their experimental data and the equations means that they are not entirely accurate and as such a level of uncertainty exists. This level of uncertainty makes it impossible to undertake an in-depth investigation into the modelling of nearfield longitudinal wake profiles using the Savitsky Wake Equations alone, as the exact solution is not known.

\section{AIMS \& OBJECTIVES}

The primary aim of this study was to perform an extensive investigation into the nearfield longitudinal wake profiles of a high-speed planing hull. The characteristics of the flow was examined, looking to establish trends linked to variations in speed and trim. The work then focused on investigating the accuracy of Savitsky's Wake Equations when used out of range, and the applicability of the Linear Wake Assumption to establish what region, if any, it holds validity. The evaluation was made through a comparison of the $\mathrm{CL}$ and $\mathrm{QB}$ determined by each method with experimental data.

A number of objectifies have been identified to achieve this aim:

1. Perform a novel experimental program extracting the nearfield wake profiles of planing hulls, as no data exists in the public domain.

2. Provide insight into the challenges of small-scale testing of high-speed hulls.

3. Investigate the complex flow of the wake pattern developed by a planing hull.

4. Investigate the accuracy of both methods at modelling the nearfield longitudinal wake profiles.

5. Provide future researchers with detailed validation data. 


\section{METHODOLOGY}

The global methodology of the study was broken down into three stages:

The first stage was to conduct an experimental test program to generate data. This took place at the Kelvin Hydrodynamics Laboratory, operated by the Department of Naval Architecture, Marine and Ocean Engineering at the University of Strathclyde, Glasgow. The test tank is $76 \mathrm{~m}$ long, $4.6 \mathrm{~m}$ wide and $2.5 \mathrm{~m}$ deep, and has a carriage capable of a maximum speed of $4.5 \mathrm{~m} / \mathrm{s}$. Small-scale testing was necessary due to the limitation of the maximum carriage speed. This required careful consideration and presented a unique set of problems. An approach utilising sonic probes mounted on a gantry frame was employed to measure the wake profile. In addition to the profile measurements, resistance, lift and trimming moment data was also collected. Following the gathering of experimental data, an in-depth experimental uncertainty analysis was also performed so the data may be used with confidence.

The second stage of the work was to investigate Savitsky's Wake Equations and the Linear Wake Assumption. A MATLAB script was developed, debugged and validated for Savitsky's Wake Equations, whilst simple trigonometry and the Excel software was used for the Linear Wake Assumption. All cases that were tested by the experimental program were replicated using both methods, allowing a comparison over a range of conditions.

The third stage was to perform a comprehensive comparison between the experimental, empirical and simplified data, allowing a detailed evaluation of all the approaches employed. The results were analysed and discussed, presenting a full analysis upon the applicability of each method.

\section{EXPERIMENTAL SET UP}

This section details the experimental set up, providing information on the model and conditions for which it was tested. The instrumentation employed to capture the nearfield longitudinal wake profiles is discussed, highlighting the advantages and drawbacks of the chosen approach.

\subsection{The Model}

The model was a simple prismatic hull form, featuring a constant deadrise. It was tested in a fully planing condition in calm water, so only the underwater section was important as there were no waves interacting with the remainder of the hull. Planing hulls often feature a variable deadrise ranging from the deep-V at the bow to the relatively flat aft section. The underwater section when fully planing predominantly features the flatter aft section in which little deadrise variation is present. As such, the underwater portion of any planing hull can be well represented by a prismatic wedge.

The model was built by the technicians employed at the Kelvin Hydrodynamics Laboratory. It was constructed of high-density foam that was milled by a CNC machine, before being faired and painted. The lines plan is presented in Figure 2.

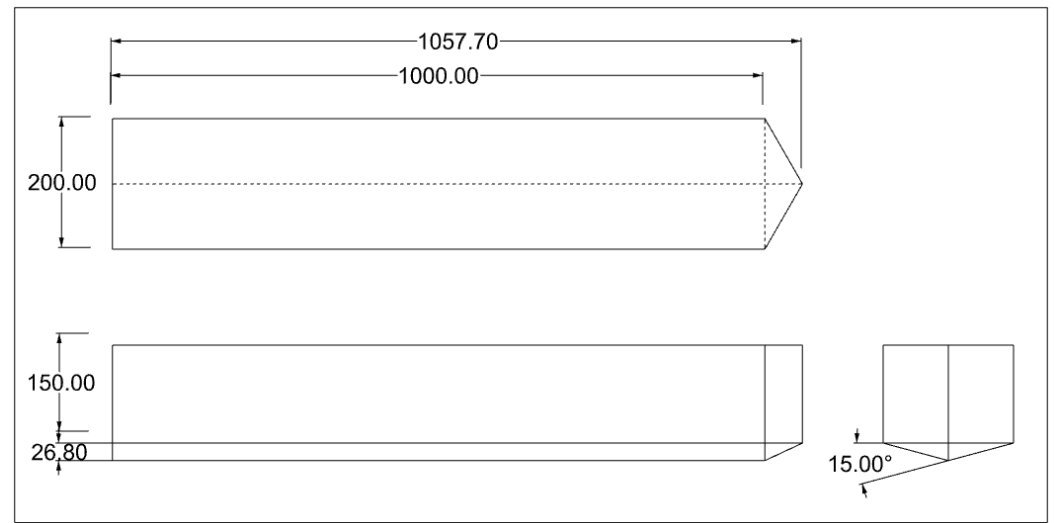

Figure 2 - Lines Plan of Model (Linear Dimensions in $\mathrm{mm}$ ) 


\subsection{Test Matrix}

An experimental test matrix was defined to cover a broad a range of hull positions. This allowed for a robust validation case across a number of conditions. The matrix comprised of three hull positions being tested at four speeds. This resulted in 12 test cases for which a total of 175 runs were completed. The different hull positions were made up of three trim angles, with the sinkage for each being altered to provide larger variations in the displacement and wetted lengths. The hull parameters for each hull position are detailed in Table 1.

Table 1 - Hull Parameters

\begin{tabular}{|l|r|r|r|}
\hline Trim $(\tau)[$ Deg] & 4 & 3 & 1.9 \\
\hline Draft $[\mathrm{mm}]$ & 39 & 33 & 27 \\
\hline Wetted Keel Length $[\mathrm{mm}]$ & 545 & 630 & 814 \\
\hline Wetted Chine Length $[\mathrm{mm}]$ & 172 & 119 & 0 \\
\hline Volume $\left[\mathrm{cm}^{3}\right]$ & 1004.93 & 850.61 & 739.19 \\
\hline Wetted Area $\left[\mathrm{cm}^{2}\right]$ & 742.36 & 776.16 & 849.78 \\
\hline
\end{tabular}

\subsection{Set Up}

The model was fixed in sinkage and trim. This increased the difficulty of positioning the model correctly but allowed for a more controllable scenario where the trim could be set to a desired value.

To alter the trim two $10 \mathrm{~mm}$ plates were attached to the top of the model, forming a hinge. This hinge established a centre of rotation located $610 \mathrm{~mm}$ from the transom and $196.8 \mathrm{~mm}$ above the keel. Bolts at the back of this hinge could be adjusted to vary the trim angle. The model was mounted to an Ogawa Seiki 6-Axis Load Cell and test rig via these hinged plates, with measurements being recorded and analysed with the Spike 2 software package. Cameras were set up with both photographs and video recordings being taken to allow further post processing.

For all test cases the wake profile was measured using sonic probes mounted on a gantry behind the model. Sonic probes had a number of issues; namely it was unknown if they would be capable of making readings at high speeds, or if they would suffer from dropouts. It is known that sonic probes are more accurate than wave capacitance wires for long wavelength waves and respond better to small changes in amplitude, however, for steeper waves sonic probes are prone to drop outs (Callander, 2015). A drop out is when the signal does not return to the probe after reflecting off the wave, causing the signal to be lost for brief periods. The second issue with sonic probes is that they may allow for a limited number of measurements to be made at each run as an array of probes may interact with each other, giving false readings. The final issue with using sonic probes is that accurately locating them proved to be extremely challenging.

Visual inspection of the wake generated by the hull established that the flow did not feature any overly steep waves, and as such the sonic probe should be capable of measuring them without suffering from dropouts. It was established that sonic probes were capable of working at high speeds. Tests at $4 \mathrm{~m} / \mathrm{s} \& 4.5 \mathrm{~m} / \mathrm{s}$ showed that while the probes did suffer from occasional dropouts, they produced enough data to extract an accurate reading in almost every case. Where the location of the dropout resulted in no useable data being recorded a repeat run would usually resolve the issue. Mounting the sonic probes as close to the surface of the water as recommended in their manuals led to the fewest number of drop outs as the signal had less vertical distance to travel and as such, the probe moved a shorter distance forwards in the time it took for the signal to return. Testing also revealed that it was possible to use two sonic probes simultaneously without interference, provided they have at least $400 \mathrm{~mm}$ longitudinal separation.

A gantry was constructed and mounted to the test carriage to allow the position of the probes to be altered both accurately and rapidly. The gantry allowed only 1 -axis of motion at a time and was constrained to slide only in the $x$ and $y$ directions. This simplified the initial placement of the probes as they could be placed at a known location, such as the transom, with adjustments via the gantry then being made to locate them for each measurement. The layout of the gantry is presented in Figure 3. 


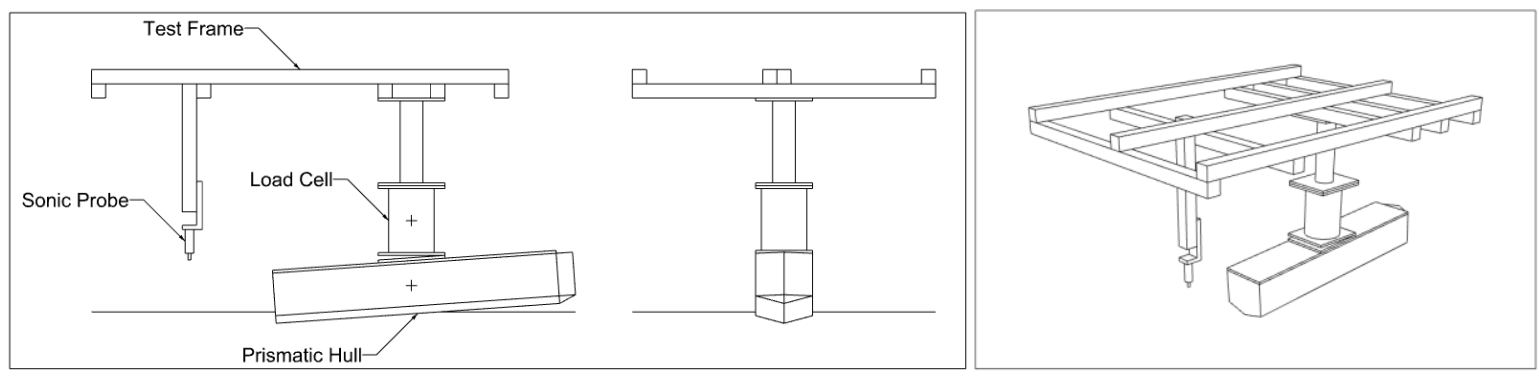

Figure 3 - Gantry Step Up for One Sonic Probe

\section{SAVITSKY'S WAKE EQUATIONS}

As has been previously discussed, Savitsky and Morabito (2010) developed empirical equations that quantitatively define the longitudinal surface wake profiles aft of a prismatic planing hull. The equations were developed using physical phenomena that can be associated with the development of the wake profile, rather than using computer-based methods to arbitrarily fair the data.

The resulting equations took the following form:

$$
H=0.17\left(A+0.03 L_{k} \tau^{1.5}\right) \sin \left(\frac{\pi}{C_{V}}\left(\frac{X}{3}\right)^{1.5}\right)
$$

Where ' $A$ ' is a constant defined as follows:

- $\quad$ Centreline Profile $\left(\beta=10^{\circ}\right)$ :

$$
A=1.5
$$

- Centreline Profile $\left(\beta=20^{\circ} \& 30\right)$ :

$A=2.0$

- Quarter Beam Profile $\left(\beta=10^{\circ}, 20^{\circ} \& 30\right): A=0.75$

Where:

$\begin{array}{lll}\beta & - & \text { Deadrise [Degrees] } \\ A & - & \text { Constant } \\ L_{k} & - & \text { Wetted Keel [Beams] } \\ \tau & - & \text { Trim Angle [Degrees] } \\ H & - & \text { Wake Profile Height above Extended Keel Line [Beams] } \\ C_{V} & - & \text { Speed Coefficient } \\ X & - & \text { Distance aft of Transom [Beams] }\end{array}$

The paper sets out a strict set of limits for the equations, stating that it is essential that the application of any data-based equations is limited to the range and combination of parameters used by the test program. Whilst this holds true and generally the use of empirical equations out of range should be treated with caution, they may maintain some level of accuracy. This depends how far out of range the equations are being used, with accuracy usually diminishing the further the case is from the original data. Secondly, it depends upon the strength of the relationships used to develop the empirical equations. As physical phenomena were used to develop the Savitsky Wake Equations, they should maintain a higher level of accuracy when used out of range. The limits are as follows:

- $10^{\circ} \leq \beta \leq 30^{\circ}$

- $3^{\circ} \leq \tau \leq 4^{\circ}$

- $\quad L_{k} \geq 0.10+\frac{\tan \beta}{\pi \tan \tau}$

- $\quad 0.017 L_{K} \tau^{1.5} \geq 0.18$

- $L_{K}<3.5 B \quad \beta=20^{\circ} \& 30^{\circ}$

- $L_{K}<2.5 B \quad \beta=10^{\circ}$ 
- $4 \leq C_{v} \leq 8$

- $X \leq 3 B$

Over the course of the present study these limits were violated to allow a judgment to be made upon the accuracy of the Savitsky Wake Equations when used out of range. The cases that were studied broke the following limits:

- $\tau=1.9^{\circ}$

The trim $(\tau)$ was lower than the lower limit of 3

The wetted keel $\left(L_{k}\right)$ was 4.07, larger than the limit of 3

The speed coefficient $\left(C_{v}\right)$ ranged from 1.43 to 3.21 , smaller than the limit of 4

- $\tau=3^{\circ}$

The wetted keel $\left(L_{k}\right)$ was 3.15, larger than the limit of 3

The speed coefficient $\left(C_{v}\right)$ ranged from 1.43 to 3.21 , smaller than the limit of 4

- $\tau=4^{\circ}$

The speed coefficient $\left(C_{v}\right)$ ranged from 1.43 to 3.21 , smaller than the limit of 4

For the $3^{\circ}$ case the $L_{k}$ term exceeding the limit of 3 by 0.15 was determined to have a negligible impact upon the results through a sensitivity study.

For the $1.9^{\circ}$ case the $L_{k}$ term exceeds the limit by a larger amount. This is accountable to the low trim angle and the fact that as trim angle decreases, $L_{k}$ increases.

The parameter considered the furthest out of range in all cases was the speed coefficient. Unfortunately, due to the limitations of the test tank there was no solution to this. The carriage was incapable of higher speeds, and as such to increase $C_{v}$ would require a model with a smaller beam. This was not feasible as the size of the model used had already led to a number of issues, as discussed in Section 8.1. To decrease the size further would amplify these issues.

\section{LINEAR WAKE ASSUMPTION}

The linear wake assumption was originally proposed by Lorne Campbell, a naval architect with 36 years' experience specialising in high speed craft (Danielsson and Strømquist, 2012). It was made as a means of determining how the forebody wake would intersect with the aftbody of a planing hull and is only assumed valid for the region close to the transom of the hull.

It makes the assumption that at high speeds the high density of water results in the fluid having too much inertia to 'move out the way' of an incoming hull. Instead, it is proposed that the surface layer is 'scraped off' by the hull and thrown aside as spray, leaving the underlying streamlines undeflected. These undeflected streamlines would remain running parallel to the original freesurface.

Danielsson and Strømquist (2012) were the first researchers to develop an analytical model for stepped hulls using the linear wake assumption, stating it was reasonable at high speeds and for short ventilation lengths. The assumption was found to produce an analytical tool that was capable of modelling resistance relatively well, however, this over-predicted trim by $80 \%$ when compared to experiments.

Dashtimanesh et al. (2017) then also went on to use the linear wake assumption, once again looking to develop an analytical model for stepped hulls. They found using the assumption led to a reasonable agreement between their mathematical results and experimental data. They once again found that the developed model was unreliable at predicting trim, resulting in a 36\% average error. They reasoned that this may be due to the linear wake assumption being incapable of appropriately modelling the fluid flow separation from the step. The research concluded that there exists an urgent need to conduct an extensive set of experiments for various stepped hulls to extract the flow pattern behind the steps. This is one of the key motivations for the present work, and while it does not go as far as extracting the flow pattern and developing a new approach to modelling it, the work does investigate the performance of existing methods in an attempt to highlight the applicability of each and broaden the scope of knowledge on the topic. 


\section{EXPERIMENTAL UNCERTAINTY}

In all experimental testing it is important to ensure that all potential sources of uncertainty are considered, with steps taken to minimise these where possible. Test procedures should be carefully planned to avoid the accidental introduction of uncertainties. While post-processing experimental data all identified sources of uncertainty should be quantitatively assessed to determine their effect on the gathered data. It is through careful planning, mitigation and analysis of uncertainties that researchers can ensure high confidence levels when drawing conclusions from their results. Detailed uncertainty analysis ensures that data is not misinterpreted and that is used appropriately. It is also of high importance when the data gathered is being used to validate any other tools. The ITTC has published extensive recommendations and guidelines in respect to uncertainty analysis in tank testing (ITTC, 2014).

\subsection{Problems Associated with Small-Scale Testing}

Experimentally testing high-speed vessels further complicates an already difficult process, substantially adding to the considerations that must be given attention. Difficulties arise from the fact that the majority of hydrodynamic facilities are not well suited to high-speed testing. There are of course some facilities that are more than capable of carrying out high-speed tests, although these are by nature large and as such are expensive. The main issues faced by hydrodynamics laboratories when undertaking high-speed testing is producing high carriage speeds and having sufficient runway to allow the carriage to accelerate and make measurements. Towing carriages that are capable of high speeds add to the expense and complexity of the facility.

If a large facility capable of high speeds is not available, or practical then it is possible to mitigate problems of speed and runway by following a small-scale testing approach. Following Froude similarity it is possible to model higher speed vessels by reducing the size of the model without increasing the carriage speed. As mentioned, the Kelvin Hydrodynamics Laboratory was restricted by its maximum carriage speed of $4.5 \mathrm{~m} / \mathrm{s}$, so a small-scale testing approach was adopted.

Testing small-scale models amplifies a number of sources of uncertainty, making it vital that a detailed assessment is made to understand the effect upon the results. The impact of small-scale testing on different categories of uncertainty was considered carefully before beginning experimental work to allow mitigation where possible.

- Geometry Uncertainty - A potential change in volume due to construction uncertainties becomes more significant.

- Installation Uncertainty - Installation becomes more challenging as the effect of errors is amplified considerably due to the fact that any error is proportionally larger.

- Calibration Uncertainty - There is a level of uncertainty associated with the calibration of all instruments. This can be assessed, quantified and will remain constant for all tests carried out using that equipment. This uncertainty becomes larger relative to the result of a small-scale testing programme, as the measured result is small.

- Repeat Uncertainty - There is a level of noise associated with experimental readings, and due to the nature of experimental testing no two runs will produce the exact same reading due to this noise. This can be assessed as repeat uncertainty. In a manner similar to that of calibration uncertainty this becomes more significant when small forces are being measured.

There is little control over calibration and repeat uncertainty other than selecting the appropriate equipment and ensuring that testing procedures are stringently followed. Geometry uncertainty was controlled by ensuring that a suitably accurate method of construction was used, with care being taken at all times to minimise any potential errors. The most controllable yet prominent source of uncertainty was the installation uncertainty. When the model was installed much thought was given to the fact that any errors would have considerable effect upon the results. Multiple checks and measurements were made during the installation process to ensure the model was positioned correctly before testing proceeded. 


\subsection{Uncertainty Analysis Procedure}

The uncertainty analysis followed the methodology and procedures laid out by the ITTC (ITTC, 2014). Where the ITTC did not specify how to quantify a source of uncertainty, it was attempted to follow the same ideology in the adopted approach. This approach attempts to identify and quantify all sources of uncertainty, before combining them to determine the effect upon the result.

\subsection{Uncertainty Results}

The calculated uncertainties are displayed in

Table 2. The values of uncertainty in resistance $\left(\mathrm{F}_{\mathrm{X}}\right)$, lift $\left(\mathrm{F}_{\mathrm{Z}}\right)$ and trimming moment $\left(\mathrm{M}_{\mathrm{Y}}\right)$ were individually calculated for each individual test condition. The presented resistance uncertainty is made up of components arising from positioning, tachometer, water temperature, calibration and repeatability. Lift and Trimming moment uncertainties are made up of components arising from calibration and repeatability. In addition to the presented uncertainties, the calculated uncertainty for the sonic probe measurements was $0.55 \mathrm{~mm}$.

Table 2 - Experimental Uncertainty

\begin{tabular}{|l|r|r|r|r|r|r|r|r|r|r|r|r|}
\hline & \multicolumn{9}{|c|}{$\tau=4$} & \multicolumn{5}{c|}{$\tau=3$} & \multicolumn{5}{c|}{$\tau=1.9$} \\
\hline & \multicolumn{1}{|c|}{$2 \mathrm{~m} / \mathrm{s}$} & \multicolumn{1}{|c}{$\mathrm{m} / \mathrm{s}$} & $4 \mathrm{~m} / \mathrm{s}$ & $4.5 \mathrm{~m} / \mathrm{s}$ & $2 \mathrm{~m} / \mathrm{s}$ & $3 \mathrm{~m} / \mathrm{s}$ & $4 \mathrm{~m} / \mathrm{s}$ & $4.5 \mathrm{~m} / \mathrm{s}$ & $2 \mathrm{~m} / \mathrm{s}$ & $3 \mathrm{~m} / \mathrm{s}$ & $4 \mathrm{~m} / \mathrm{s}$ & $4.5 \mathrm{~m} / \mathrm{s}$ \\
\hline & & & & & & & & & & & & \\
\hline Fx [N] & 1.68 & 2.70 & 4.50 & 5.33 & 1.10 & 2.22 & 3.01 & 3.71 & 1.38 & 2.76 & 4.19 & 4.67 \\
\hline $95 \%$ Confidence & $12.23 \%$ & $9.06 \%$ & $7.08 \%$ & $6.78 \%$ & $17.95 \%$ & $14.04 \%$ & $9.82 \%$ & $8.78 \%$ & $14.54 \%$ & $10.95 \%$ & $7.56 \%$ & $7.52 \%$ \\
\hline Value [N] & 0.21 & 0.25 & 0.32 & 0.37 & 0.20 & 0.31 & 0.30 & 0.33 & 0.20 & 0.30 & 0.32 & 0.35 \\
\hline & & & & & & & & & & & & \\
\hline Fz [N] & 3.04 & 9.58 & 15.60 & 20.82 & 1.93 & 6.96 & 10.23 & 12.85 & -0.01 & 3.34 & 3.04 & 3.81 \\
\hline $95 \%$ Confidence & $6.46 \%$ & $3.25 \%$ & $2.73 \%$ & $2.17 \%$ & $9.86 \%$ & $4.93 \%$ & $3.80 \%$ & $3.08 \%$ & $1444.95 \%$ & $7.60 \%$ & $5.28 \%$ & $4.63 \%$ \\
\hline Value [N] & 0.20 & 0.31 & 0.43 & 0.45 & 0.19 & 0.34 & 0.39 & 0.40 & -0.15 & 0.25 & 0.16 & 0.18 \\
\hline & & & & & & & & & & & & \\
\hline My [Nm] & 0.10 & 1.25 & 2.65 & 3.74 & 0.08 & 1.10 & 2.08 & 2.74 & -0.50 & 0.20 & 0.12 & 0.32 \\
\hline 95\% Confidence & $151.44 \%$ & $11.82 \%$ & $6.34 \%$ & $4.48 \%$ & $159.77 \%$ & $13.41 \%$ & $8.86 \%$ & $5.72 \%$ & $29.51 \%$ & $66.64 \%$ & $132.59 \%$ & $46.92 \%$ \\
\hline Value [Nm] & 0.15 & 0.15 & 0.17 & 0.17 & 0.13 & 0.15 & 0.18 & 0.16 & -0.15 & 0.13 & 0.16 & 0.15 \\
\hline
\end{tabular}

A detailed breakdown of each uncertainty component is shown in Appendix A. When this is consulted it can be seen that the largest uncertainties for resistance arose from positioning the model, from the calibration of the dynamometer and from repeatability. The other components were considered negligible. These calculated uncertainties highlight the prominence of issues with small scale testing, as previously discussed.

The calculated absolute values of each uncertainty are comparable with both the examples given by the ITTC and those published in the literature. When the percentage value is considered, it appears that there is little confidence in the results and that a poorly executed experimental program was conducted. For example, there is a $1444 \%$ uncertainty in the lift measurement of tau $=1.9^{\circ}, \mathrm{v}=2 \mathrm{~m} / \mathrm{s}$ which seem to be implausible, however, this is due to the fact that the measurements are very small. This is the prominent issue when conducting small scale testing as there is no way of lowering these uncertainties further. The results may still be used with some level of confidence, it is just important to consider and understand the uncertainties associated with them.

\section{RESULTS}

The following section first discusses and presents the experimental resistance, lift and trimming moment results, before comparing and discussing the results of each of the methods of calculating the longitudinal wake profiles. While only certain cases are presented here, the full data set may be found in the Appendices. Following this, the quantitative wake profile data from each method is analysed. Qualitative wake profile data of the experimental tests is also be presented in the form of photographs and evaluated. All graphs are presented with error bars as calculated in the Experimental Uncertainty sections. 
The wake profile plots are presented in a format consistent with Savitsky and Morabito (2010), where the origin represents the point where the keel meets the transom and the horizontal axis in line with the keel, as seen in Figure 4. The distance aft of the transom, and height of the wake profile have been nondimensionalised by beam in all figures.

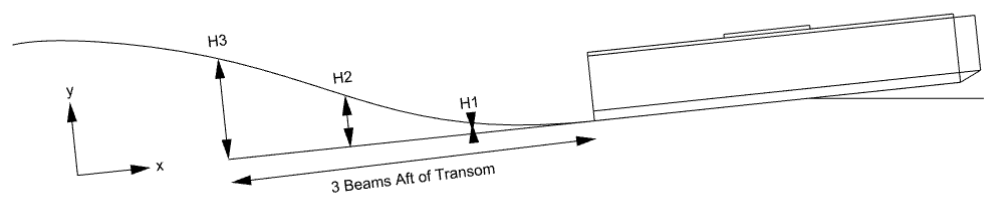

Figure 4 - Results Reference Axis

\subsection{Resistance}

The choice of hull positions was selected in order to provide a broad range of conditions for which the wake profiles could be evaluated. As such there were no systematic changes between each of the conditions tested, and no real conclusions can be drawn from a comparison between the measured forces of each. Had the condition of the hull been maintained between each trim angle it may be expected that that the resistance would vary proportionally with trim angle. This is not the case, however, due to the large changes to the wetted surface area that were due to the changes made to each test position.

It can be seen that the resistance increases in an approximate linear manner with speed for all conditions. When a linear trend line is fitted to the data it returns an $R^{2}$ value of 0.99 for all trim angles. This agrees with Ma et al. (2013), who found that once a hull was in the fully planing regime there was a linear increase in resistance between two resistance crests. Similar trends can be seen in the results of Taunton, Hudson and Shenoi, (2010). Despite this apparently linear trend, had a larger speed range been examined humps and hollows would become apparent, as is the nature of the resistance curve.

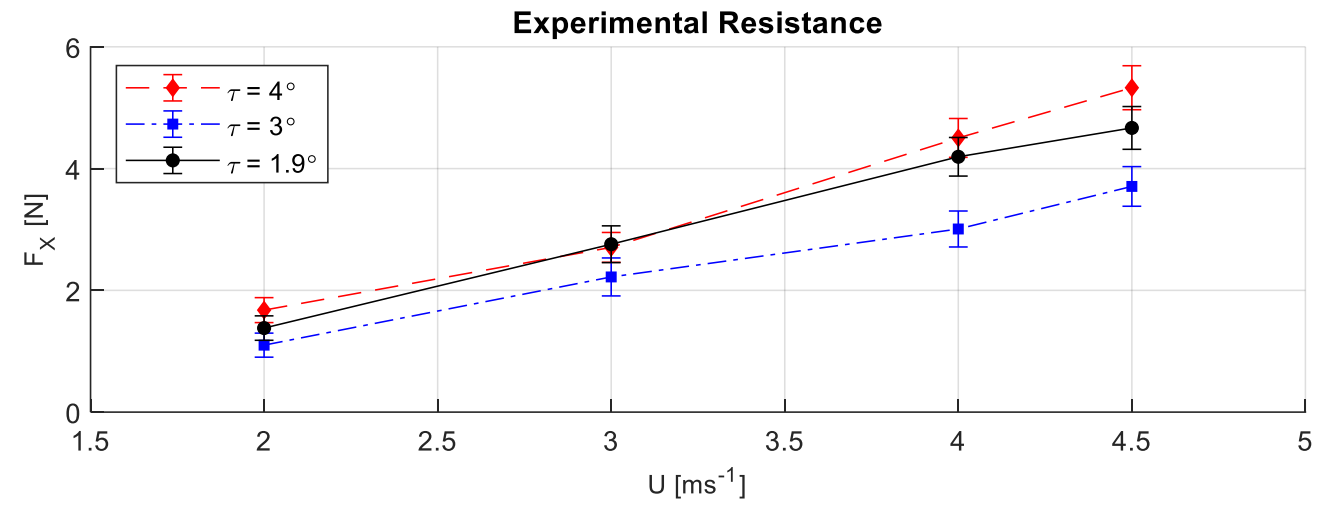

Figure 5 - Experimental Resistance Results

\subsection{Lift}

When a hull is subject to high speeds, the lift generated can be attributed two effects:

- The buoyant contribution that is accountable to the static pressures corresponding to the hull position and the displaced fluid.

- The dynamic lift, which is accountable to the forces caused by the moving fluid upon the hull.

Due to the setup of the experiments only the dynamic lift is presented. The fixed nature of the model means that the hull is not in its equilibrium position in any of the test cases. 
The results from the experimental measurements for lift are displayed by Figure 6 . As can be seen the lift increases with both trim angle and speed. When considering a lifting surface, it is well known that increasing the angle of attack will increase both the lift generated and the induced drag. These results agree with those of Ghadimi, Tavakoli and Dashtimanesh (2014), who systematically studied the effects of different parameters on the lift of a prismatic planing hull, finding lift increased with both trim angle and speed coefficient. In a manner similar to that discussed for resistance, had the condition of the hull been maintained between different trim angles it may be expected that the lift would vary proportionally with the trim angle.

The lift for $3^{\circ}$ and $4^{\circ}$ varies linearly with speed, with a linear data fit to both conditions returning an $R^{2}$ value of 0.99 . It was expected that lift would also vary linearly for $1.9^{\circ}$, however, it is seen to plateau above 3 metres per second and remain relatively constant.

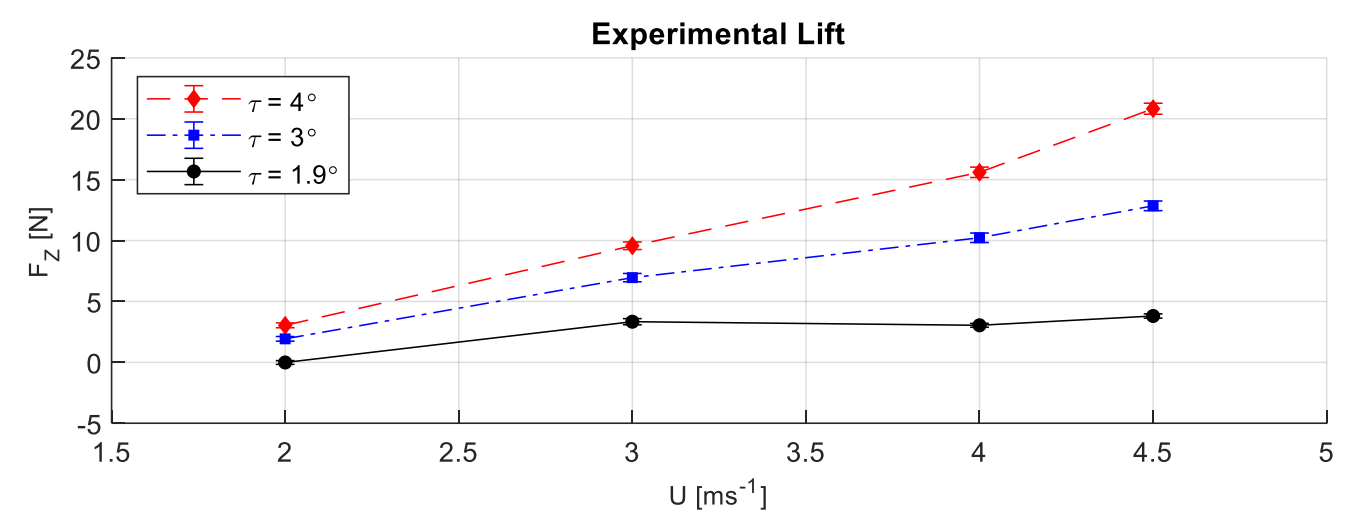

Figure 6 - Experimental Lift Results

\subsection{Trimming Moment}

Two moments act upon the planing hull, with one due to the resistance force and one due to the lift force. It can be seen that the total moment is more coupled to the lift than resistance, with the results of $1.9^{\circ}$ showing trends closely linked to those of lift. This is because the longitudinal distance between the attachment point of the load cell and the centre of lift is far greater than the vertical moment arm between the attachment point and the resistance force, giving the lift force a larger influence upon the trimming moment.

The moment for $3^{\circ}$ and $4^{\circ}$ is once again shown to be linear while the moment for $3^{\circ}$ plateaus above 3 metres per second, due to the fact that the lift measurement for these conditions also plateaus.

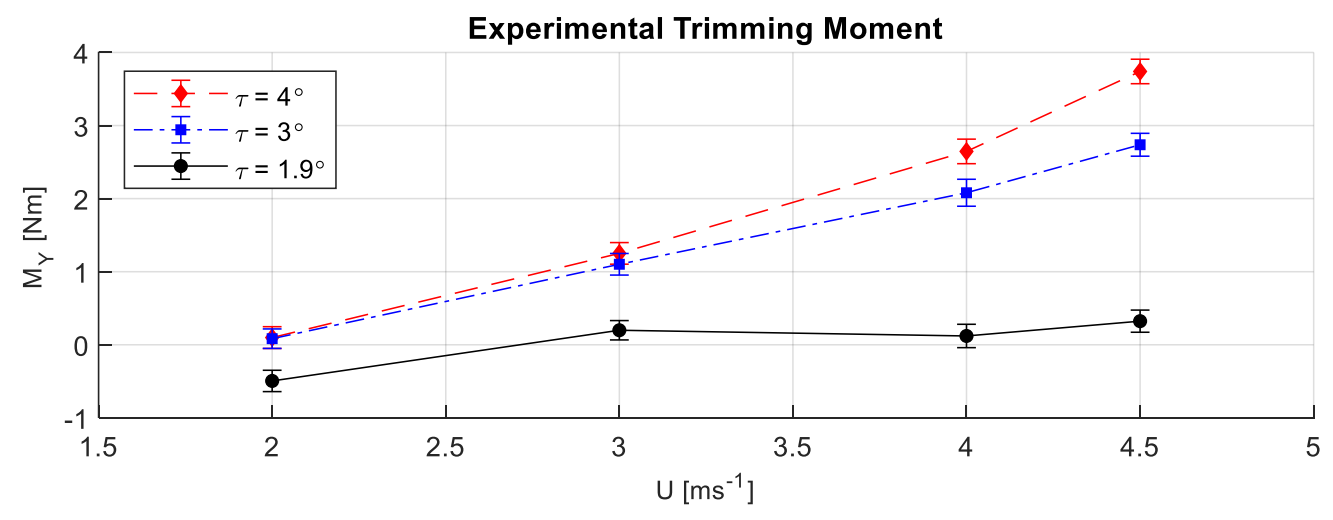

Figure 7 - Experimental Trimming Moment Results

\subsection{Centerline Wake Profiles}

This section presents the experimental results, discussing the characteristics of the longitudinal wake profiles and the trends that are apparent. Graphs are then presented, comparing the experimental profiles to those 
calculated by Savitsky's Wake Equations and the Linear Wake Assumption. Following this there is discussion upon the results of each method.

\subsubsection{Experimental Results}

In the scope of the study, trim and speed were the two factors that were varied, with three trim angles and four speeds being tested. The results of the experimentally measured wake profiles for all trim angles at $2 \mathrm{~ms}^{-1}$ and at $4.5 \mathrm{~ms}^{-1}$ are shown in Figure 8.
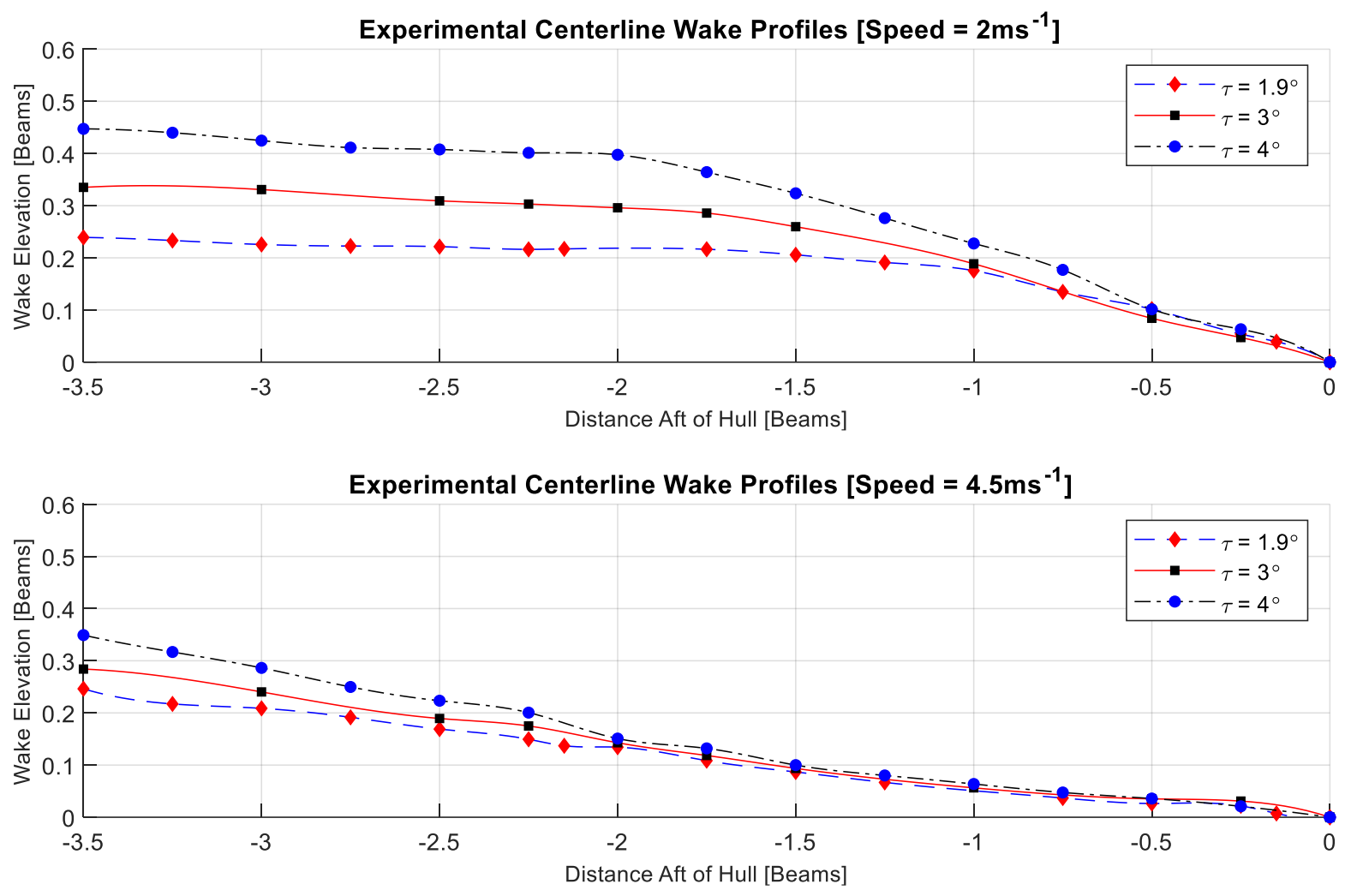

Figure 8-Experimental Centreline Wake Profiles

It was observed that as the trim angle increases for a fixed speed, the height of the wake profile increases in what appears to be a proportional manner, as seen in Figure 8. When this is investigated further and the results are divided by the trim, it is shown that the wake profiles for a given speed collapse together. This shows the three datasets to be near pure linear transformations of each other. The collapsed data for the $3 \mathrm{~ms}^{-1}$ condition $^{-1}$ is presented in Figure 9. Similar trends became apparent when other speeds were considered. While it is noted that the collapse of the results for the $1.9^{\circ}$ profile is not as perfect as the $3^{\circ}$ and $4^{\circ}$ profiles this may be attributed to the level of uncertainty present in small scale testing, and the figure still proves linearity with trim. The idea of linearity between wake profiles was first presented by Doctors (2018) who manipulated and presented the experimental data of Korvin-Kroukovsky et al. (1948b, 1948a, 1949).

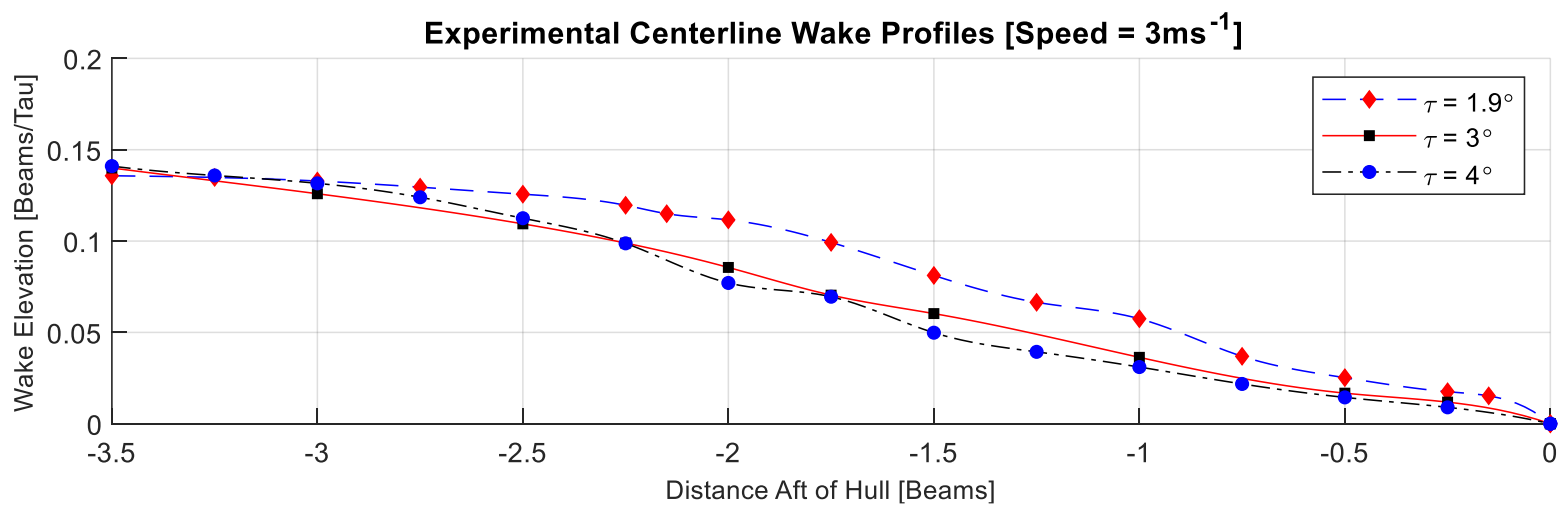


Additionally, this trend is in line with the findings of both Savitsky and Morabito (2010) and Callander (2015). The growth in wake height with speed is due to an increased downwash velocity, defined as:

$$
V_{\text {down }}=U \sin \tau
$$

Equation 2

Where:

$\begin{array}{lll}V_{\text {down }} & - & \text { Downwash Velocity [Meters per Second] } \\ U & - & \text { Vessel Speed [Meters per Second] } \\ \tau & - & \text { Trim Angle [Degrees] }\end{array}$

As downwash velocity increases, the energy initially imparted to the flow as it leaves the stern of the hull is larger, and consequently so is the wake height. As the trim angle increases, the draft at the transom becomes larger, which may be an additional factor of the increasing wake height with trim angle. A larger draft increases both the hydrostatic pressure at the transom and the volume of the fluid displaced by the hull. This is pointed out by Savitsky and Morabito (2010), who explain that these increased initial disturbances result in a larger wake profile. As the speed increases, the difference in wake height due to the increasing trim becomes smaller. At a speed of $2 \mathrm{~ms}^{-1}$ the difference between the $1.9^{\circ}$ profile and the $4^{\circ}$ profile is $41.62 \mathrm{~mm}$, whereas this decreases to $20.58 \mathrm{~mm}$ at $4.5 \mathrm{~ms}^{-1}$.

As the speed increases it has two notable effects upon the wake profile. The first is that the profiles elongate longitudinally, becoming flatter and decreasing in amplitude for a given $\mathrm{x}$-position. This is a similar finding to that of Savitsky and Morabito (2010), who found that for otherwise identical conditions, increasing the speed would "stretch" the profile. This stretching phenomenon is implied by Equation 1 and may also be explained by classic-water wave theory, where the wavelength is proportional to the square of the speed. It has the effect of decreasing the profile height at a given $\mathrm{x}$-position as the speed increases. Likewise, the results of Callander (2015) show the same trend, with the authors expanding upon it. The study investigated wave cuts that were transversely offset from the hull allowing the entire longitudinal profile to be plotted, showing this stretching phenomenon in more detail as the wave peak of each condition was captured. Had the peak of the profile been captured for all speed conditions and the results plotted using $g X / U^{2}$ as the abscissa, it is expected that the peak would occur at the same location for all cases.

The second effect of the increased speed is that amplitude of the peak of the wave will increase. This is occurs through the same mechanism by which the wake amplitude increases with trim angle, and is due to the increased downwash velocity Callander (2015). Despite the peak of the wave increasing in amplitude, the wake profile still decreases in elevation in the region being studied due to the elongation phenomena.

When the photos in Figure 10 are examined the elongation of the wake profile that was visible in the wake elevation plots can be clearly seen. The flow pattern remains constant for all speeds; however, it clearly becomes 'stretched' as the speed increases. It should be noted that in the right edge of the green band marks $100 \mathrm{~mm}$ intervals from the transom, in order to give scale to the images. 

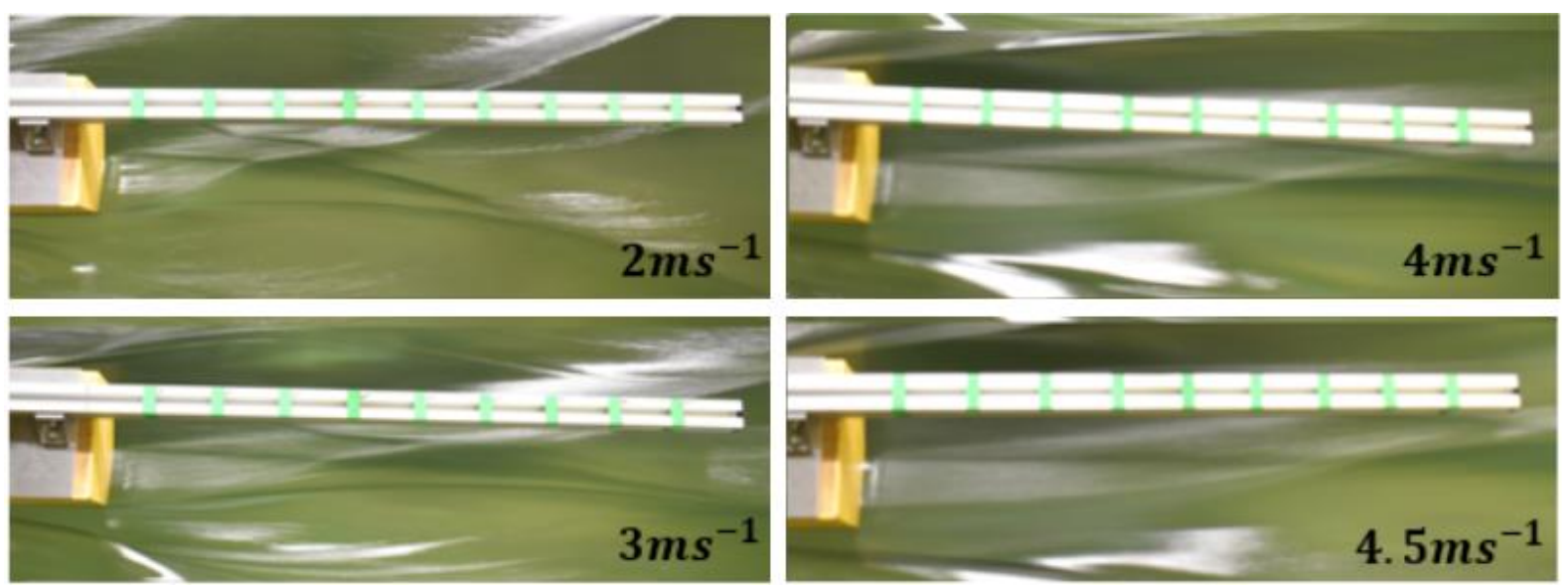

Figure 10 - Photos of Wake Pattern $(\tau=4)$

\subsubsection{Comparison Graphs}

The results for all cases will not be presented here as 20 individual graphs would be required to do so, which are instead detailed in Appendix D. The data presented in this section has been selected to highlight the best and worst-fit scenarios.

It should be noted that the experimental uncertainty in the measurements of the wake profile amplitudes was $0.56 \mathrm{~mm}$. This uncertainty is not displayed as error bars on the graphs as they are not visible due to the scale.

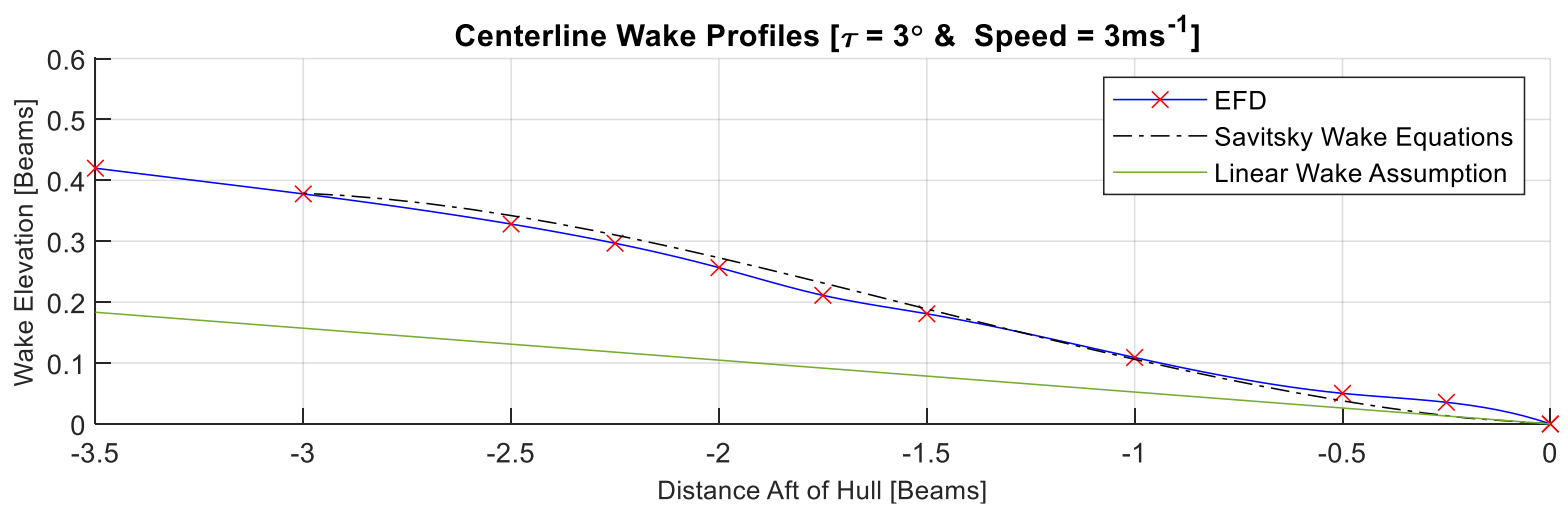

Figure 11 - Best-Fit Savitsky Wake Equation Case

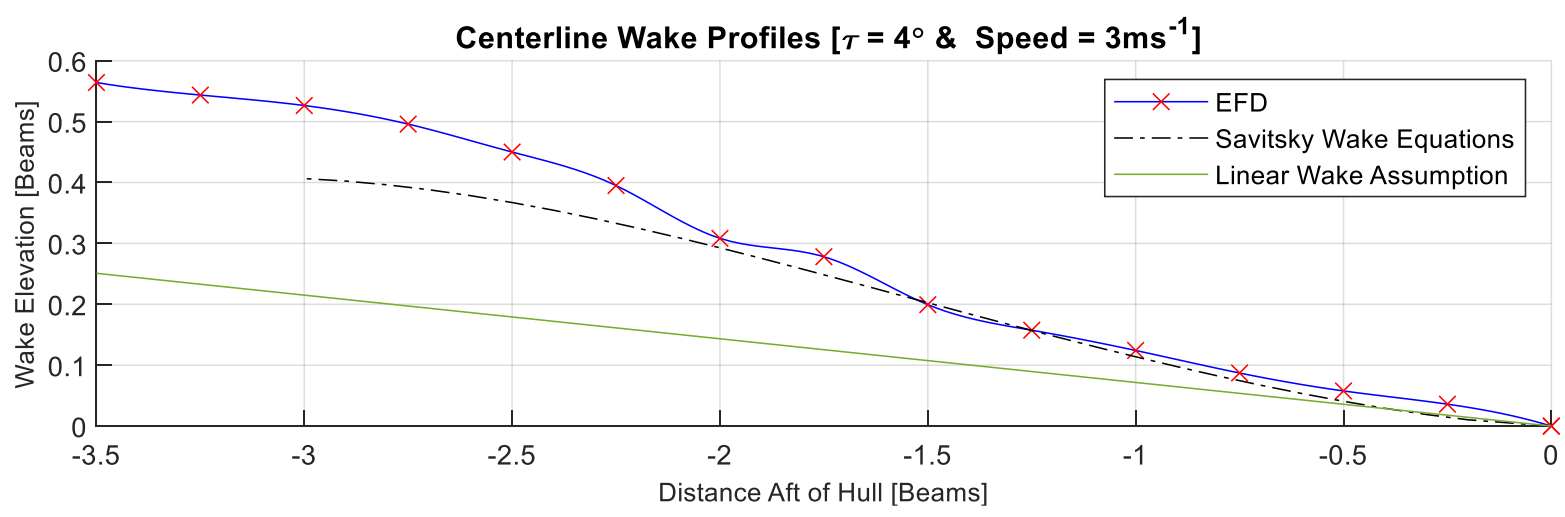

Figure 12 - Worst-Fit Savitsky Wake Equation Case 


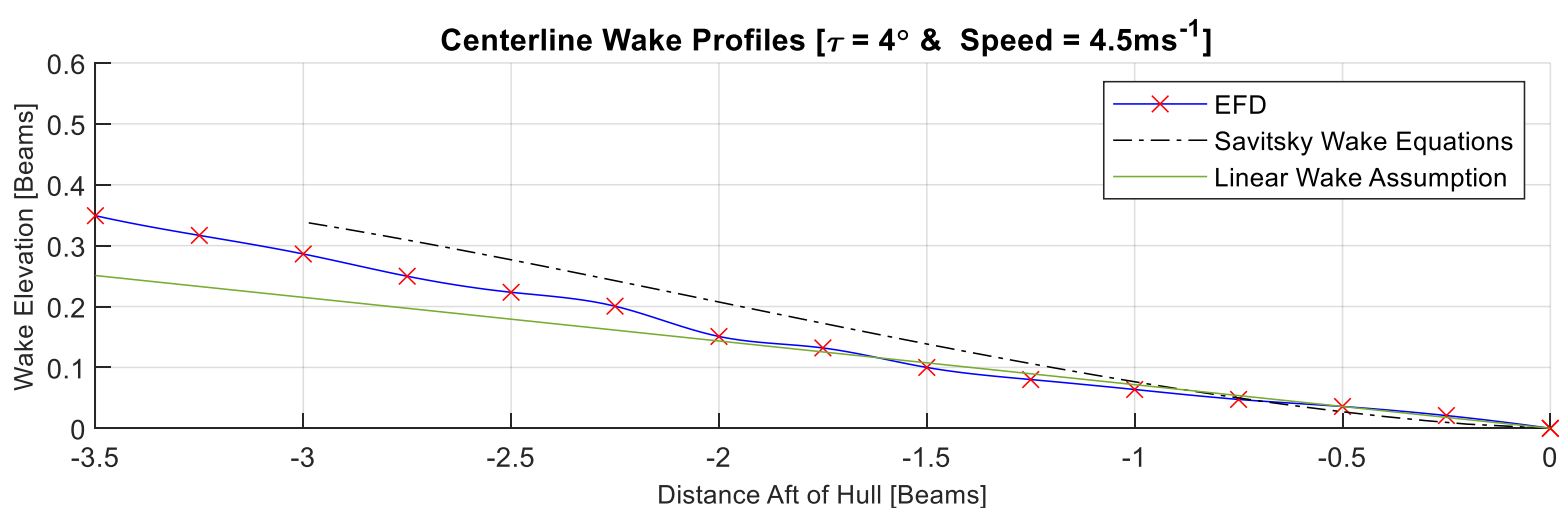

Figure 13 - Best-Fit Linear Wake Assumption Case

\subsubsection{Discussion of Savitsky Wake Equation}

In general, the accuracy of Savitsky's equations is found to increase with trim angle. This is because as the trim angle increases the number of limits that are violated by the case decreases, as discussed in Section 6 . With fewer limits being broken, the empirical equations are being used for conditions more in line with those with which they were derived, and as such their accuracy increases. This trend is seen for all speeds, aside the $3 \mathrm{~ms}^{-1}$ case, where a trim of $3^{\circ}$ is found to be very well modelled by the wake equations.

The case in which the wake equations are the least representative is at a trim of $1.9^{\circ}$ at $2 \mathrm{~ms}^{-1}$. For this case, the equations are the furthest from their limit of application and it is seen that the results are unrepresentative of the experimental data. The plots of these results may be seen in Appendix D. Both the profile shape and its maximum amplitude are incorrect. As mentioned, when the trim angle increases so too does the accuracy of the wake equations. They are not capable of accurately modelling the correct profile at any trim angle for $2 \mathrm{~ms}^{-1}$, but there is a significant improvement and the maximum amplitude also becomes more representative for the $4^{\circ}$ case. Despite the equations being shown to be inaccurate for all trim conditions at $2 \mathrm{~ms}^{-1}$ they are seen to be more representative when applied closer to the transom, being accurate until $0.3 \mathrm{~m}$ aft for $1.9^{\circ}, 0.4 \mathrm{~m}$ aft for $2^{\circ}$ and $0.5 \mathrm{~m}$ aft for $4^{\circ}$.

As the equations were not capable of modelling the wake profile accurately at $2 \mathrm{~ms}^{-1}$ the results for this condition are excluded from the discussion on varying speed. When the speed is varied, the trend of the profiles behaves differently for each trim. At $1.9^{\circ}$ the difference between experimental data and the calculated values remains constant. For both the $3^{\circ}$ and $4^{\circ}$ cases, it is seen that as the speed increases the predicted wake profile grows in amplitude in comparison to the experimental data. This is surprising as it was theorised that as $4.5 \mathrm{~ms}^{-1}$ was closest to the lower limit of $C_{v}$ for all trim cases it would produce the most accurate results. The maximum differences between the empirical and experimental data are presented in Table 3.

Table 3 - Maximum Differences between Savitsky's Wake Equations and Experimental Data

\begin{tabular}{|c|l|l|l|}
\hline & $3 \mathrm{~ms}^{-1}$ & $4 \mathrm{~ms}^{-1}$ & $4.5 \mathrm{~ms}^{-1}$ \\
\hline$\tau=1.9^{\circ}$ & $16.85 \mathrm{~mm}$ & $16.16 \mathrm{~mm}$ & $16.61 \mathrm{~mm}$ \\
\hline$\tau=3^{\circ}$ & $0.24 \mathrm{~mm}$ & $11.40 \mathrm{~mm}$ & $15.14 \mathrm{~mm}$ \\
\hline$\tau=4^{\circ}$ & $-23.97 \mathrm{~mm}$ & $4.41 \mathrm{~mm}$ & $10.53 \mathrm{~mm}$ \\
\hline
\end{tabular}

When Savitsky and Morabito (2010) originally derived the equations, they found that there was good agreement between the equations and the test data, with a maximum deviation of 0.08 beams for the $\mathrm{CL}$ profiles, corresponding to an absolute deviation of $16 \mathrm{~mm}$ for the model used in this work. Considering how far out of range the equations were being applied, they performed surprisingly well, producing an average maximum 
deviation of 0.064 beams. Whilst they should be used with caution, it is fair to say that there is a reasonable correlation between the empirical method and the experimental data. In almost all cases, it is seen the accuracy of the equations improves as distance from the transom decreases, which designers of stepped hulls should bear in mind. These equations will be more representative and introduce smaller errors when used with shorter ventilation lengths.

\subsubsection{Discussion of Linear Wake Assumption}

In all cases the linear wake assumption under-predicts the amplitude of the $\mathrm{CL}$ wake profile. It is shown to be the least accurate method to be investigated, however, there are regions in which it is shown to have an acceptable level of accuracy. For all trim cases at the lower speeds of $2 \& 3 \mathrm{~ms}^{-1}$ the linear wake profile was found to be inaccurate and unrepresentative of the wake profile. One of the underlying assumptions it is based upon is that the hull is travelling at high speed, so this was to be expected.

It is seen that as the trim angle increases, so too does the accuracy of the linear wake assumption. At $4.5 \mathrm{~ms}^{-1}$ it may be considered accurate less than $0.15 \mathrm{~m}$ aft of the transom for $1.9^{\circ}$, whereas at the same speed with a trim of $4^{\circ}$ it is accurate until $0.4 \mathrm{~m}$ aft of the transom. This trend is visible at all speeds.

As the speed increases, the accuracy is seen to improve in the region close to the transom. For $4^{\circ}$ at $3 \mathrm{~ms}^{-1}$ it is accurate for $0.3 \mathrm{~m}$ aft or the transom. This increases to $0.4 \mathrm{~m}$ aft when the speed increases to $4.5 \mathrm{~ms}^{-1}$. This trend is apparent at all trim angles. Once the distance aft of the transom is increased beyond the region in which the linear wake assumption may be considered accurate, the error in the prediction increases rapidly, so a significant level of caution should be exercised if implementing this method. Without further experimental work it is not possible to make a recommendation upon the region in which the linear wake assumption is shown to be accurate.

As the linear wake assumption is more capable of modelling the elongated wake profile of high-speed cases, it is theorised that as the speed increases this method's region of applicability will increase for all trim angles. A more extensive study examining the higher speed ranges is required to gauge the point at which the linear wake assumption may be considered entirely valid.

\subsection{Quarter Beam Wake Profiles}

This section presents the experimental results, discussing the characteristics of the longitudinal wake profiles and the trends that are made apparent. Graphs are then presented, comparing the experimental profiles to those calculated by Savitsky's Wake Equations and the Linear Wake Assumption. Following this there is discussion upon the results of each method.

\subsubsection{Experimental Results}

The same trends that were established for the $\mathrm{CL}$ profiles can be seen in the $\mathrm{QB}$ profiles. As the speed increases the profile is seen to elongate, resulting in a reduction in wake height. As the trim increases so too does the wake height, due to the increased transom immersion and downwash velocity. As is visible in Figure 15 , the quarterbeam profiles collapse to one curve when divided by the trim angle in a manner similar to the centreline profiles, further proving that the linearity concept holds true. It was not possible to obtain QB profiles for all conditions due to time restrictions. As such, none are presented for $1.9^{\circ}$.

The most predominant difference between the $\mathrm{CL}$ profiles and the QB profiles is that whereas the CL profiles are for the most part smooth curves, the QB profiles feature more disturbances. These disturbances occur around $0.4 \mathrm{~m}$ aft of the transom in all cases aside those at $2 \mathrm{~ms}^{-1}$. They are most noticeable for the $3 \mathrm{~ms}^{-1}$ case, as presented in Figure 14. 


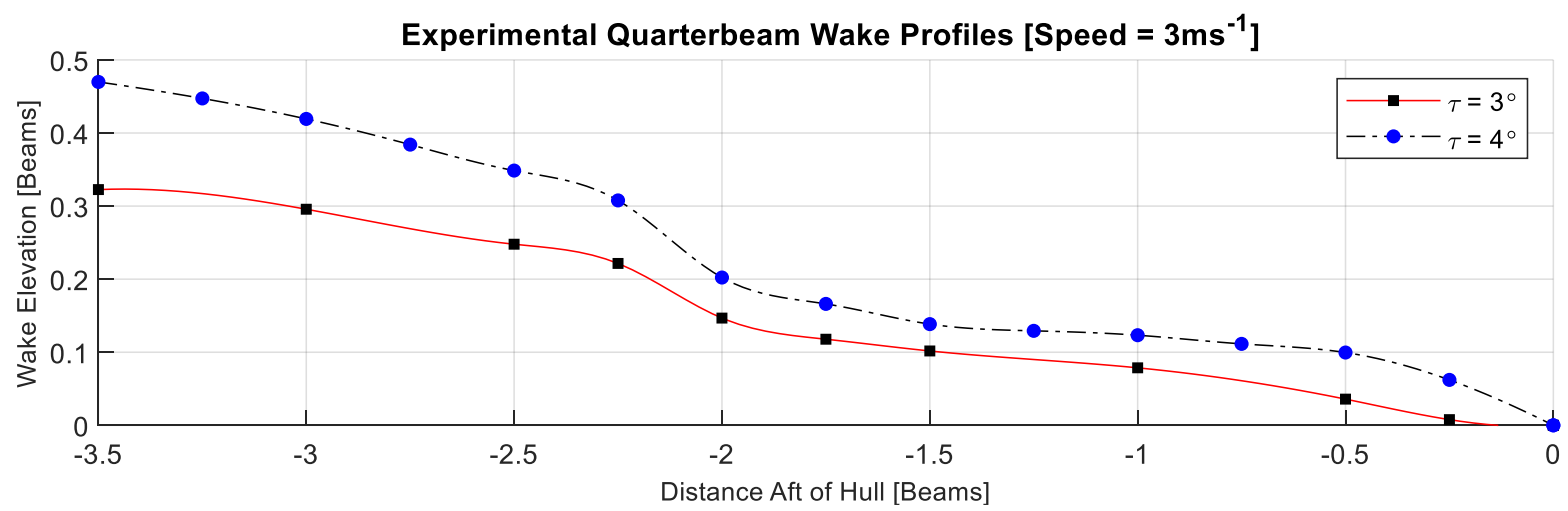

Figure 14 - Experimental Quarterbeam Wake Profiles

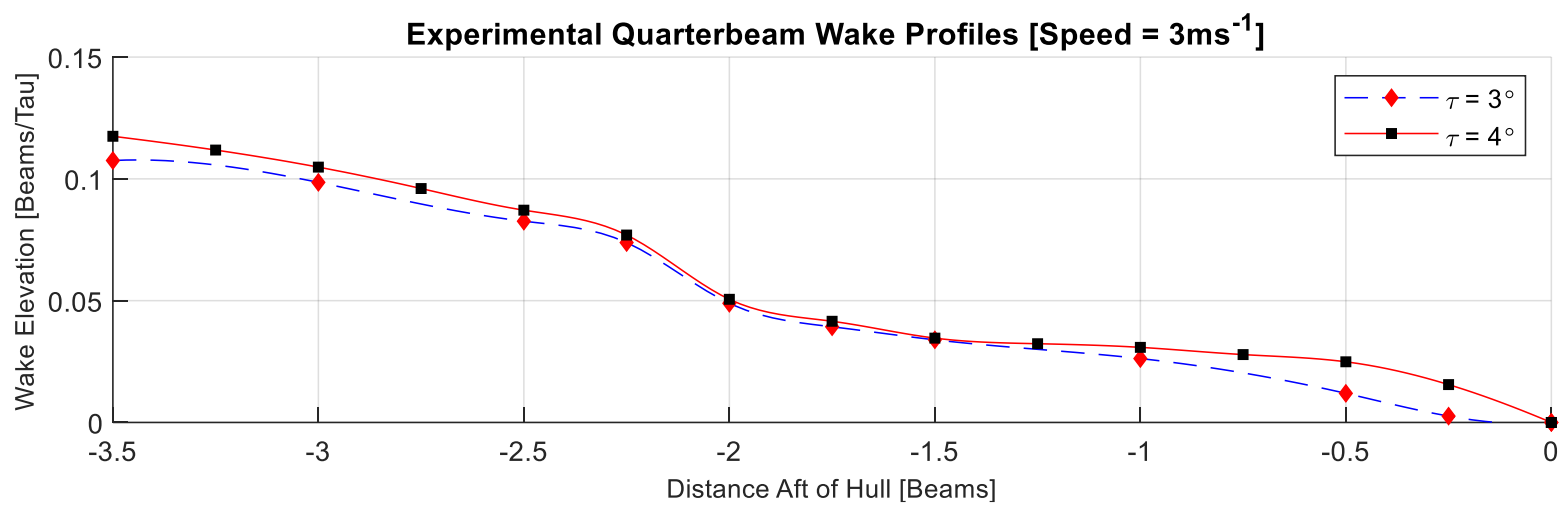

Figure 15 - Experimental Quarterbeam Wake Profiles Collapsed by Trim

When the photographs of the experiments are examined, as seen in Figure 10, it can be seen that around $0.4 \mathrm{~m}$ aft of the hull, the quarter beam longitudinal slice will intersect with one of the flow feature lines as it curves into the centreline. A similar scenario exists at all speeds close to the $0.4 \mathrm{~m}$ aft position. As the wake pattern elongates with speed the characteristics of the flow feature line change, which is why the level of disturbance varies from case to case. It is also possible to see that whilst the feature line still exists in the $2 \mathrm{~ms}^{-1}$ condition, it has far less influence on the flow elevation and crosses the QB line closer to the transom than $0.4 \mathrm{~m}$ aft. This is why the disturbance is not visible on the $Q B$ wake profile for this case.

\subsubsection{Comparison Graphs}

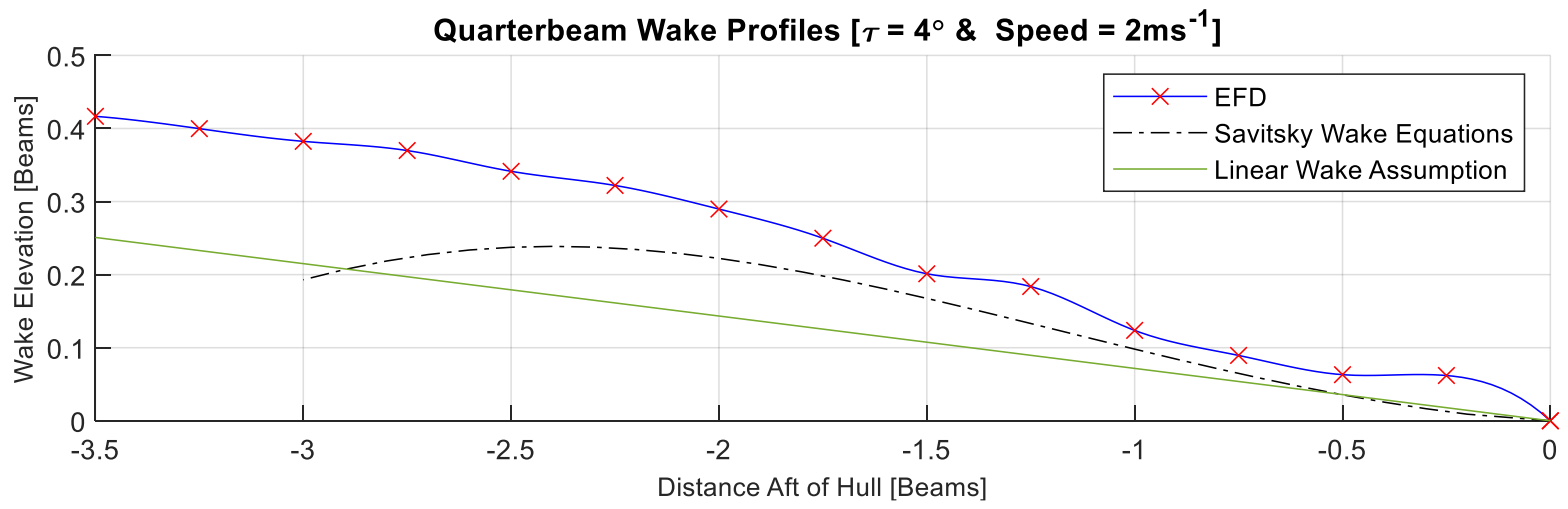



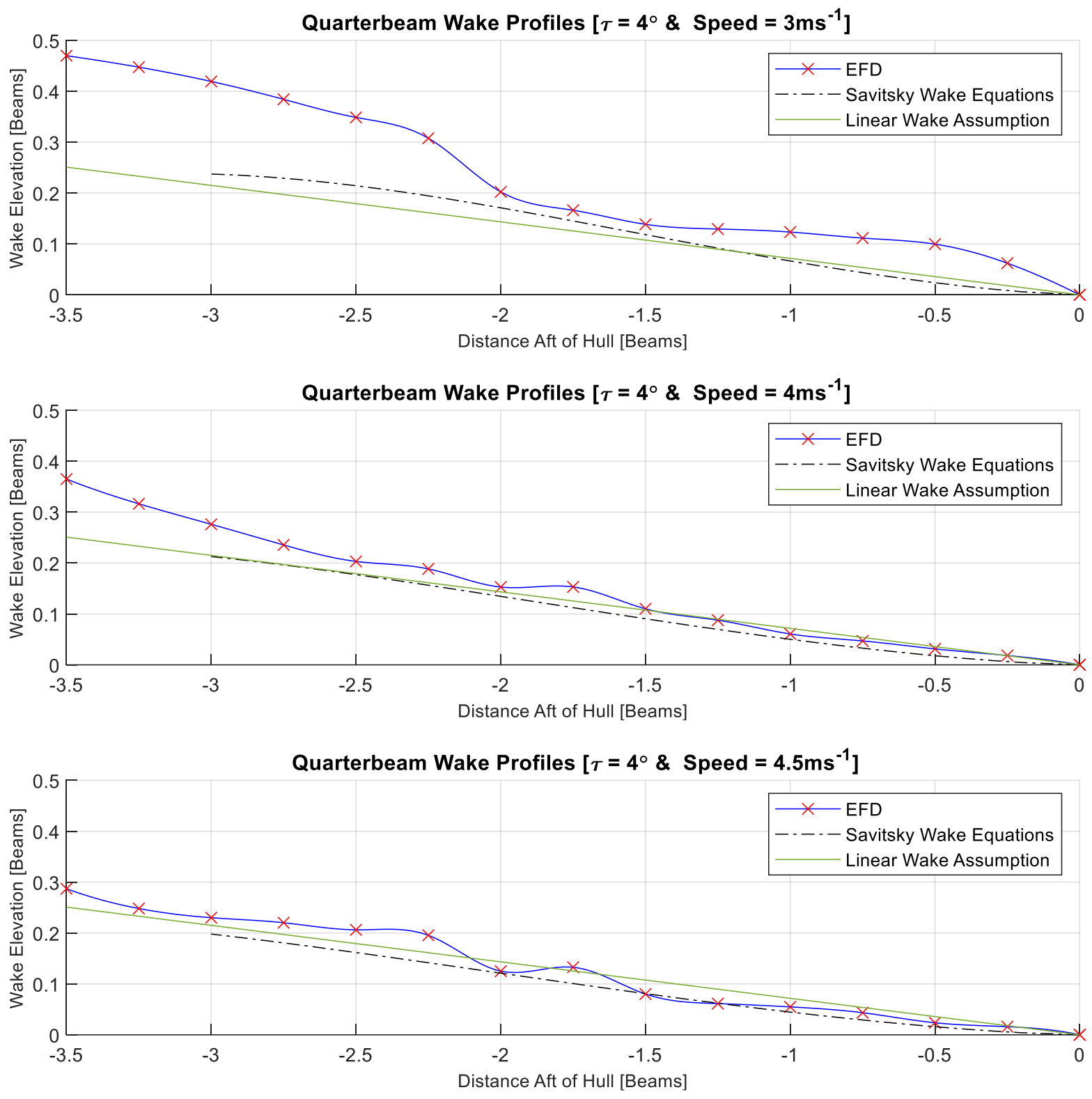

Figure 16 - Qarterbeam Profiles [ $\tau=4$ ]

\subsubsection{Savitsky Wake Equation Results Discussion}

When the results are examined the QB profiles calculated by the Savitsky Wake Equations are more accurate at the higher speeds of $4 \& 4.5 \mathrm{~ms}^{-1}$ for both trim conditions, with accuracy being shown to improve with speed. The calculated profiles are more representative than the for the $\mathrm{CL}$ profiles, displaying a very good correlation between the experimental and empirical data for these cases. At the lower speeds of $2 \& 3 \mathrm{~ms}^{-1}$ the accuracy decreases and it is apparent that the equations are not able to model the whole profile at lower speeds. In a manner similar to that of the CL profiles, the accuracy of the equations improves as distance from the transom decreases for these lower speed cases, and they produce reasonable results until $0.4 \mathrm{~m}$ aft of the hull.

At $3^{\circ}$ the empirical equations results agree very well with the experimental data for both $4 \& 4.5 \mathrm{~ms}^{-1}$. At $4^{\circ}$ the results are slightly less accurate, but still show a very good correlation. With only two trim conditions being tested it is not possible to establish any trends linked to the trim of the hull.

When Savitsky and Morabito (2010) developed the empirical equations it was found that there was good agreement between the equations and the test data, with a maximum deviation of 0.04 beams for the $Q B$ profiles. When the feature lines present in the experimental data is ignored and the general trends of the experimental data are considered for these cases, the maximum deviation from the experimental data is 
generally less than this value. Whilst the empirical equations are not capable of modelling the feature lines and local disturbances of the experimental data, they are relatively accurate across all cases.

\subsubsection{Linear Wake Assumption Results Discussion}

In a manner similar to the $\mathrm{CL}$ profiles, the linear wake assumption is shown to under-predict the amplitude of the QB profiles. It is once again considered the least accurate or robust of the two methods, although it should be noted that it performs better at modelling the $\mathrm{QB}$ profiles than it did for the $\mathrm{CL}$ profiles. In certain regions, it is more accurate than Savitsky's wake equations, however, these regions are very limited and due to the lack of robustness and level of inaccuracy for other regions, it is difficult to use this method with confidence.

The accuracy follows the same trends as discussed in the $\mathrm{CL}$ section, increasing with both speed and trim. The difference between the $\mathrm{QB}$ and $\mathrm{CL}$ profiles is that the for the $\mathrm{QB}$ case the linear wake assumption is shown to be considerably more accurate.

At the slowest speed tested, the linear wake assumption is unrepresentative of the QB profile. At $3 \mathrm{~ms}^{-1}$ it begins to exhibit a reasonable level of accuracy for the region close to the transom. As the speed increases, so too does the size of the region in which it may be considered accurate, until $4.5 \mathrm{~ms}^{-1}$ where it is seen to have a good correlation with the experimental data for the entire $0.7 \mathrm{~m}$ region being investigated. Once outside the region in which it is considered accurate at slower speeds, the level of deviation from the experimental data grows rapidly. Once again it is not possible to make a recommendation upon the region in which the Linear Wake Assumption may be considered from the data available.

It is theorised that as the speed increases beyond those tested, the linear wake assumptions accuracy will increase further. It has been shown to be considerably more capable of modelling the QB profile than for the $\mathrm{CL}$ profile in all cases, at times produces the best correlation with experimental data, however, the lack of robustness leads to a lack of confidence.

\section{CONCLUDING REMARKS}

This study has set out to evaluate the characteristics of the nearfield longitudinal wake profile of a planing hull, and to assess the capabilities of Savitsky's Wake Equations and the Linear Wake Assumption in modelling this. The primary application of this was as an aid to the designers of stepped hulls, allowing them to determine how the wake of the forebody would intersect with the afterbody with a greater degree of confidence. Accurately calculating the intersection of the flow from the forebody is vital in order to calculate the forces acting upon the afterbody, and thus for performance prediction of stepped hulls. Previous studies have highlighted an urgent need to extract the flow pattern from behind the step of a stepped hull for this application (Dashtimanesh, Tavakoli and Sahoo, 2017). Experimentally measuring this flow pattern with the presence of the afterbody is extremely challenging and is something that has not been achieved to date. As such this study employed the simplification suggested by Savitsky and Morabito (2010) and assumes the presence of the afterbody has no effect upon the flow pattern of the forebody.

An extensive literature review revealed that there have been very limited previous studies looking to investigate the nearfield longitudinal wake profile of a planing hull. Existing experimental work investigating this region of flow focused almost entirely upon seaplane floats, with only one study testing prismatic planing hulls (Savitsky and Morabito, 2010). The aforementioned study did not directly publish the experimental results, instead deriving empirical formulations for the calculation of the wake profiles.

A novel experimental test program was conducted for a broad range of conditions, measuring the nearfield longitudinal wake profiles to provide validation data, which has subsequently been published as an aid to future researchers. Sonic probes were employed as an unobtrusive method of measuring the wake elevation aft of the hull, ensuring the presence of the instrumentation had no effect upon the wake profile. Due to speed limitations it was necessary to employ a small-scale testing methodology, for which the associated difficulties were identified and mitigation strategies implemented. An extensive experimental uncertainty analysis was then performed to ensure confidence in the results, and revealing that the greatest source of error associated with small-scale testing was the placement of the model. 
The experimentally extracted wake profiles displayed trends that were in agreement with previous experimental studies on near and mid-field wake profiles (Savitsky and Morabito, 2010; Callander, 2015). Larger angles of trim increased the downwash velocity, which in turn produced a wake profile with a larger elevation. Larger speeds were shown to cause the wake profile to elongate longitudinally.

The empirical formulations as developed by Savitsky and Morabito (2010) were then investigated to determine how they performed when used out with their limits of application, as defined by the parameters of the test program used for their development. It was shown that while the equations were not applicable at lower speeds, they featured a surprising level of accuracy at higher speeds. In almost all cases, the deviation between the calculated profiles and the experimental data was smaller than the maximum deviation between the equations and the data used to generate them. Despite the remarkable level of accuracy, caution should still be exercised when using empirical equations outwith their limits. A recommendation is proposed to restrict the region in which the equations are employed to two beams aft, rather than the original three beams aft when using them out or range as this region was shown to maintain the highest level of accuracy.

Additionally, the Linear Wake Assumption, as proposed by Lorne Campbell was investigated. This was found to be considerably less accurate, producing large errors for nearly all cases. At higher speeds it was shown to increase in accuracy for the QB profiles. This trend was apparent for the CL profiles as well, with accuracy shown to improve with speed. One of its fundamental assumptions is that the speed is high enough to 'scrape' off the top layer of water, leaving the underlying streamlines parallel to the freesurface. It is likely that the speeds investigated over the course of this work were not high enough to fulfil this, leading to the lack of accuracy displayed by the method.

It is a highlighted area of future work to investigate the linear wake assumption at higher speeds, and to determine when it may be considered valid. In order to rapidly generate data and mitigate the expense and time of running a more extensive experimental test program employing computational means provides a promising solution. The experimental data generated by the present study may provide validation data for a computational study, and be used to provide insight into the merits and limitations of state of the art Computational Fluid Dynamics (CFD) in its ability to model the nearfield longitudinal wake profile of a high-speed planing hull.

\section{ACKNOWLEDGMENTS}

Experimental Results were obtained at the Kelvinside Hydrodynamics Laboratory (https://www.strath.ac.uk/engineering/navalarchitectureoceanmarineengineering/ourfacilities/kelvinhydrody namicslaboratory/), based at the University of Strathclyde. Many thanks are given to Grant Dunning, Steven Black and Saishuai Dai for their assistance and expertise.

The work presented in this paper is taken from the first author's doctoral thesis. The first author gratefully acknowledges the scholarship provided by the University of Strathclyde, which fully supports his PhD. 


\section{REFERENCES}

Callander, C. K. (2015) 'Wake prediction behind planing hulls', in Transactions - Society of Naval Architects and Marine Engineers, pp. 450-457.

Danielsson, J. and Strømquist, J. (2012) CONCEPTUAL DESIGN OF A HIGH-SPEED SUPERYACHT TENDER HULL FORM ANALYSIS AND STRUCTURAL OPTIMIZATION Marina system Centre for Naval Architecture. Available at: https://www.diva-portal.org/smash/get/diva2:612181/FULLTEXT01.pdf (Accessed: 27 August 2019).

Dashtimanesh, A., Tavakoli, S. and Sahoo, P. (2017) 'A simplified method to calculate trim and resistance of a two-stepped planing hull', Ships and Offshore Structures. Taylor \& Francis, 12(1), pp. S317-S329. doi: 10.1080/17445302.2016.1262809.

Doctors, L. . (2018) Hydrodynamics of High-Performance Marine Vessels, Volume 2. second. CreateSpace, an Amazon.com Company.

Doctors, L. J. (2003) 'Hydrodynamics of the ow behind a transom stern', in In Twenty-Ninth Isreal Conference on Mechanical Engineering. Haifa, Isreal.

Faison, L. A. (2014) Design of a High Speed Planing Hull with a Cambered Step and Surface Piercing Hydrofoils. Available at: https://apps.dtic.mil/dtic/tr/fulltext/u2/a610449.pdf (Accessed: 20 August 2019).

Fu, T. et al. (2005) Characterization of the Steady Wave Field of the High Speed Transom Stern Ship - Model 5365 Hull Form.

Ghadimi, P. et al. (2015) 'Rooster tail depression by originating a modified transom stern form using a Reynolds averaged Navier Stokes solver', Scientia Iranica, 22(3). doi: 10.1007/0-387-24091-8.

Ghadimi, P., Tavakoli, S. and Dashtimanesh, A. (2014) 'A Mathematical Scheme for Calculation of Lift of Planing Crafts with Large Mean Wetted Length and a Comparative Study of Effective Parameters', Universal Journal of Fluid Mechanics 2, 2, pp. 35-54.

ITTC (2014) 'General Guideline for Uncertainty Analysis in Resistance Tests -7.5-02-02-02', Recommended Procedures and Guidelines.

Korvin-Kroukovsky, B. ., Savitsky, D. and Lehman, W. . (1948a) 'Wave Contours in the Wake of a 10-degree Deadrise Planing Surface', Stevens Institute of Technology Report-R-344, (November).

Korvin-Kroukovsky, B. ., Savitsky, D. and Lehman, W. . (1948b) 'Wave Contours in the Wake of a 20-degree Deadrise Planing Surface', Stevens Institute of Technology Report R-337, (June).

Korvin-Kroukovsky, B. ., Savitsky, D. and Lehman, W. . (1949) 'Wave Profile of a VEE Planing Surface, Including Test Data on a 30- degree Deadrise Surface', Stevens Institute of Technology Report R-339, (April).

De Luca, F. and Pensa, C. (2017) 'The Naples warped hard chine hulls systematic series', Ocean Engineering, 139, pp. 205-236. doi: 10.1016/j.oceaneng.2017.04.038.

Ma, W. et al. (2013) 'Test research on the resistance performance of high-speed trimaran planing hull', Polish Maritime Research, 20(4), pp. 45-51. doi: 10.2478/pomr-2013-0040.

MacPhail, D. . and Tye, W. . (1944) 'The Waves Close Behind a Planing Hull', Royal Aircraft Establishment, Farnborough Report No. Aero, (November).

Maki, K. et al. (2006) 'The transom-stern modeled as a backward facing step', in 26th Symposium on Naval Hydrodynamics. Rome, Italy.

Saunders, H. (1957) 'Hydrodynamics in Ship Design', Society of Naval Architects and Marine Engineers., 2, p. 529.

Savitsky, D. and Morabito, M. (2010) 'Surface Wave Contours Associated with the Forebody Wake of Stepped Planing Hulls', Marine Technology, 47(1), pp. 1-16.

Sottorf, W. (1932) 'Experiments with planing surfaces', National Advisory Committee for Aeronautics Technical Memorandum 661.

Taunton, D. J., Hudson, D. A. and Shenoi, R. A. (2010) 'Characteristics of a series of high speed hard chine planing 
hulls - Part 1: Performance in calm water', International Journal of Small Craft Technology, 152, pp. 55-75. doi: 10.3940/rina.ijsct.2011.b1.97.

Thornhill, E. et al. (2003) 'Planing Hull Model Tests for CFD Validation', International Shipbuilding Progress (ISP), 50(1 \& 2), pp. 5-18. 
APPENDIX A - DETAILED BREAKDOWN OF EXPERIMENTAL UNCERTAINTY

\begin{tabular}{|c|c|c|c|c|c|c|c|c|c|c|c|c|}
\hline \multicolumn{13}{|c|}{ RESISTANCE } \\
\hline \multirow[b]{3}{*}{$\mathrm{Fx}[\mathrm{N}]$} & \multicolumn{4}{|c|}{$\tau=4$} & \multicolumn{4}{|c|}{$\tau=3$} & \multicolumn{4}{|c|}{$\tau=1.9$} \\
\hline & $2 m s^{-1}$ & $3 m s^{-1}$ & $4 m s^{-1}$ & $4.5 m s^{-1}$ & $2 m s^{-1}$ & $3 m s^{-1}$ & $4 m s^{-1}$ & $4.5 \mathrm{~ms}^{-1}$ & $2 m s^{-1}$ & $3 m s^{-1}$ & $4 m s^{-1}$ & $4.5 m s^{-1}$ \\
\hline & 1.68 & 2.71 & 4.50 & 5.33 & 1.10 & 2.22 & 3.01 & 3.71 & 1.38 & 2.76 & 4.19 & 4.67 \\
\hline Positioning - Sinkage & $-2.72 \%$ & $-2.72 \%$ & $-2.72 \%$ & $-2.72 \%$ & $-2.68 \%$ & $-2.68 \%$ & $-2.68 \%$ & $-2.68 \%$ & $-2.97 \%$ & $-2.97 \%$ & $-2.97 \%$ & $-2.97 \%$ \\
\hline Positioning - Trim & $-0.48 \%$ & $-0.48 \%$ & $-0.48 \%$ & $-0.48 \%$ & $-0.50 \%$ & $-0.50 \%$ & $-0.50 \%$ & $-0.50 \%$ & $-0.69 \%$ & $-0.69 \%$ & $-0.69 \%$ & $-0.69 \%$ \\
\hline Tachometer & $0.07 \%$ & $0.07 \%$ & $0.07 \%$ & $0.07 \%$ & $0.07 \%$ & $0.07 \%$ & $0.07 \%$ & $0.07 \%$ & $0.07 \%$ & $0.07 \%$ & $0.07 \%$ & $0.07 \%$ \\
\hline Thermometer & $0.05 \%$ & $0.06 \%$ & $0.06 \%$ & $0.06 \%$ & $0.08 \%$ & $0.08 \%$ & $0.09 \%$ & $0.09 \%$ & $0.06 \%$ & $0.07 \%$ & $0.06 \%$ & $0.07 \%$ \\
\hline Dynamometer Fx & $5.30 \%$ & $3.28 \%$ & $1.97 \%$ & $1.67 \%$ & $8.37 \%$ & $4.37 \%$ & $2.91 \%$ & $2.40 \%$ & $6.43 \%$ & $3.43 \%$ & $2.12 \%$ & $1.90 \%$ \\
\hline Repeatability & $1.32 \%$ & $1.46 \%$ & $1.02 \%$ & $1.05 \%$ & $1.73 \%$ & $4.77 \%$ & $2.86 \%$ & $2.46 \%$ & $1.50 \%$ & $2.98 \%$ & $0.73 \%$ & $1.12 \%$ \\
\hline Combined Uncertainty & $6.12 \%$ & $4.53 \%$ & $3.54 \%$ & $3.39 \%$ & $8.98 \%$ & $7.02 \%$ & $4.91 \%$ & $4.39 \%$ & $7.27 \%$ & $5.47 \%$ & $3.78 \%$ & $3.76 \%$ \\
\hline 95\% Confidence & $12.23 \%$ & $9.06 \%$ & $7.08 \%$ & $6.78 \%$ & $17.95 \%$ & $14.04 \%$ & $9.82 \%$ & $8.78 \%$ & $14.54 \%$ & $10.95 \%$ & $7.56 \%$ & $7.52 \%$ \\
\hline Value $[\mathrm{N}]$ & 0.20 & 0.25 & 0.32 & 0.36 & 0.20 & 0.31 & 0.30 & 0.33 & 0.20 & 0.30 & 0.32 & 0.35 \\
\hline
\end{tabular}




\begin{tabular}{|c|c|c|c|c|c|c|c|c|c|c|c|c|}
\hline \multicolumn{13}{|c|}{ LIFT } \\
\hline & \multicolumn{4}{|c|}{$\tau=4$} & \multicolumn{4}{|c|}{$\tau=3$} & \multicolumn{4}{|c|}{$\tau=1.9$} \\
\hline & $2 m s^{-1}$ & $3 m s^{-1}$ & $4 m s^{-1}$ & $4.5 m s^{-1}$ & $2 m s^{-1}$ & $3 m s^{-1}$ & $4 m s^{-1}$ & $4.5 m s^{-1}$ & $2 m s^{-1}$ & $3 m s^{-1}$ & $4 m s^{-1}$ & $4.5 m s^{-1}$ \\
\hline $\mathrm{Fz}[\mathrm{N}]$ & 3.04 & 9.57 & 15.60 & 20.82 & 1.93 & 6.96 & 10.23 & 12.85 & -0.01 & 3.34 & 3.04 & 3.81 \\
\hline Dynamometer Fz & $2.54 \%$ & $0.81 \%$ & $0.49 \%$ & $0.37 \%$ & $3.96 \%$ & $1.09 \%$ & $0.76 \%$ & $0.60 \%$ & $-722.47 \%$ & $2.35 \%$ & $2.54 \%$ & $2.03 \%$ \\
\hline Repeatability & $2.00 \%$ & $1.41 \%$ & $1.27 \%$ & $1.02 \%$ & $2.93 \%$ & $2.21 \%$ & $1.74 \%$ & $1.42 \%$ & $1.50 \%$ & $2.98 \%$ & $0.73 \%$ & $1.12 \%$ \\
\hline Combined Uncertainty & $3.23 \%$ & $1.62 \%$ & $1.37 \%$ & $1.08 \%$ & $4.93 \%$ & $2.46 \%$ & $1.90 \%$ & $1.54 \%$ & $722.47 \%$ & $3.80 \%$ & $2.64 \%$ & $2.32 \%$ \\
\hline 95\% Confidence & $6.46 \%$ & $3.25 \%$ & $2.73 \%$ & $2.17 \%$ & $9.86 \%$ & $4.93 \%$ & $3.80 \%$ & $3.08 \%$ & $1444.9 \%$ & $7.60 \%$ & $5.28 \%$ & $4.63 \%$ \\
\hline Value [N] & 0.20 & 0.31 & 0.43 & 0.45 & 0.19 & 0.34 & 0.39 & 0.40 & -0.15 & 0.25 & 0.16 & 0.18 \\
\hline
\end{tabular}




\begin{tabular}{|c|c|c|c|c|c|c|c|c|c|c|c|c|}
\hline \multicolumn{13}{|c|}{ TRIMMING MOMENT } \\
\hline & \multicolumn{4}{|c|}{$\tau=4$} & \multicolumn{4}{|c|}{$\tau=3$} & \multicolumn{4}{|c|}{$\tau=1.9$} \\
\hline & $2 m s^{-1}$ & $3 m s^{-1}$ & $4 m s^{-1}$ & $4.5 \mathrm{~ms}^{-1}$ & $2 m s^{-1}$ & $3 m s^{-1}$ & $4 m s^{-1}$ & $4.5 \mathrm{~ms}^{-1}$ & $2 m s^{-1}$ & $3 m s^{-1}$ & $4 m s^{-1}$ & $4.5 \mathrm{~ms}^{-1}$ \\
\hline Dynamometer My & $72.26 \%$ & $5.69 \%$ & $2.69 \%$ & $1.90 \%$ & $73.96 \%$ & $6.39 \%$ & $3.44 \%$ & $2.61 \%$ & $-14.38 \%$ & $31.75 \%$ & $59.01 \%$ & $22.02 \%$ \\
\hline Repeatability & $22.62 \%$ & $1.60 \%$ & $1.68 \%$ & $1.18 \%$ & $30.19 \%$ & $2.03 \%$ & $2.80 \%$ & $1.16 \%$ & $-3.32 \%$ & $10.11 \%$ & $30.22 \%$ & $8.10 \%$ \\
\hline 95\% Confidence & $151.44 \%$ & $11.82 \%$ & $6.34 \%$ & $4.48 \%$ & $159.77 \%$ & $13.41 \%$ & $8.86 \%$ & $5.72 \%$ & $29.51 \%$ & $66.64 \%$ & $132.59 \%$ & $46.92 \%$ \\
\hline Value $[\mathrm{Nm}]$ & 0.15 & 0.15 & 0.17 & 0.17 & 0.13 & 0.15 & 0.18 & 0.16 & -0.15 & 0.13 & 0.16 & 0.15 \\
\hline
\end{tabular}


APPENDIX B - TABULATED EXPERIMENTAL RESULTS

\begin{tabular}{|c|c|c|c|c|c|c|c|c|c|c|c|c|c|c|c|c|c|c|c|}
\hline & \multicolumn{18}{|c|}{ Centreline Profiles } \\
\hline & & $x[\mathrm{~m}]$ & 0 & -0.03 & -0.05 & -0.1 & -0.15 & -0.2 & -0.25 & -0.3 & -0.35 & 0.44 & -0.43 & -0.45 & -0.5 & -0.55 & -0.6 & -0.65 & -0.7 \\
\hline \multirow{12}{*}{$\mathrm{H}[\mathrm{mm}]$} & \multirow{4}{*}{$\tau=1.9$} & $2 m s^{-1}$ & 0.0 & 7.9 & 10.8 & 20.3 & 26.9 & 35.1 & 38.2 & 41.2 & 43.3 & & 43.4 & 43.2 & 44.3 & 44.5 & 45.1 & 46.6 & 47.8 \\
\hline & & $3 m s^{-1}$ & 0.0 & 6.1 & 7.0 & 10.1 & 14.8 & 23.0 & 26.6 & 32.5 & 39.7 & 44.6 & 46.0 & 47.8 & 50.3 & 51.8 & 53.1 & 53.9 & 54.3 \\
\hline & & $4 m s^{-1}$ & 0.0 & 4.9 & 5.2 & 6.5 & 8.4 & & 16.3 & 20.5 & 26.4 & 31.0 & 33.4 & 34.6 & 39.8 & 42.9 & 46.6 & 50.0 & 53.9 \\
\hline & & $4.5 \mathrm{~ms}^{-1}$ & 0.0 & 1.5 & 4.4 & 5.3 & 7.4 & & 13.4 & 17.4 & 21.7 & 26.9 & 27.4 & 29.9 & 33.8 & 38.3 & 41.8 & 43.4 & 49.3 \\
\hline & \multirow{4}{*}{$\tau=3$} & $2 m s^{-1}$ & 0.0 & & 9.4 & 16.8 & & 37.7 & & 51.9 & 57.2 & 59.2 & & 60.6 & 61.9 & & 66.2 & & 67.0 \\
\hline & & $3 m s^{-1}$ & 0.0 & & 7.1 & 10.1 & & 21.8 & & 36.2 & 42.2 & 51.3 & & 59.4 & 65.7 & & 75.5 & & 84.0 \\
\hline & & $4 m s^{-1}$ & 0.0 & & 5.9 & 7.0 & & 14.0 & & 22.9 & 27.3 & 33.5 & & 39.4 & 43.0 & & 56.5 & & 66.6 \\
\hline & & $4.5 \mathrm{~ms}^{-1}$ & 0.0 & & 6.2 & 7.0 & & 11.3 & & 18.7 & 23.7 & 28.6 & & 35.0 & 37.9 & & 48.0 & & 56.8 \\
\hline & \multirow{4}{*}{$\tau=4$} & $2 m s^{-1}$ & 0.0 & & 12.6 & 20.3 & 35.4 & 45.5 & 55.2 & 64.7 & 72.9 & 79.5 & & 80.3 & 81.6 & 82.3 & 84.9 & 88.0 & 89.4 \\
\hline & & $3 m s^{-1}$ & 0.0 & & 7.2 & 11.5 & 17.4 & 24.8 & 31.5 & 39.9 & 55.6 & 61.7 & & 79.0 & 90.0 & 99.2 & 105.3 & 108.7 & 112.8 \\
\hline & & $4 m s^{-1}$ & 0.0 & & 5.1 & 7.7 & 10.8 & 14.5 & 18.9 & 24.2 & 32.0 & 45.3 & & 46.5 & 52.3 & 60.3 & 68.7 & 77.2 & 86.8 \\
\hline & & $4.5 \mathrm{~ms}^{-1}$ & 0.0 & & 4.2 & 7.2 & 9.5 & 12.8 & 16.0 & 20.0 & 26.4 & 30.2 & & 40.1 & 44.7 & 50.0 & 57.3 & 63.4 & 69.8 \\
\hline
\end{tabular}




\begin{tabular}{|c|c|c|c|c|c|c|c|c|c|c|c|c|c|c|c|c|c|}
\hline & \multicolumn{16}{|c|}{ Quarter Beam Profiles } \\
\hline & & $x[\mathrm{~m}]$ & 0 & -0.05 & -0.1 & -0.15 & -0.2 & -0.25 & -0.3 & -0.35 & -0.44 & -0.45 & -0.5 & -0.55 & -0.6 & -0.65 & -0.7 \\
\hline \multirow{9}{*}{$\mathrm{H}[\mathrm{mm}]$} & \multirow{4}{*}{$\tau=3$} & $2 m s^{-1}$ & 0.0 & 5.8 & 9.6 & & 17.1 & & 32.6 & 36.1 & 41.9 & 47.4 & 51.1 & & 54.9 & 0.0 & 59.0 \\
\hline & & $3 m s^{-1}$ & 0.0 & 1.6 & 7.2 & & 15.7 & & 20.4 & 23.6 & 29.3 & 44.3 & 49.6 & & 59.1 & 0.0 & 64.5 \\
\hline & & $4 m s^{-1}$ & 0.0 & 1.6 & 5.5 & & 10.8 & & 16.1 & 21.8 & 22.9 & 26.1 & 29.0 & & 41.9 & 0.0 & 53.1 \\
\hline & & $4.5 \mathrm{~ms}^{-1}$ & 0.0 & 2.3 & 4.2 & & 9.0 & & 12.0 & 19.2 & 21.3 & 27.7 & 29.4 & & 34.0 & 0.0 & 43.1 \\
\hline & & & & & & & & & & & & & & & & & \\
\hline & \multirow{4}{*}{$\tau=4$} & $2 m s^{-1}$ & 0.0 & 12.4 & 12.6 & 17.9 & 24.7 & 36.7 & 40.2 & 50.0 & 57.9 & 64.4 & 68.3 & 74.0 & 76.5 & 80.0 & 83.3 \\
\hline & & $3 m s^{-1}$ & 0.0 & 12.4 & 19.9 & 22.3 & 24.7 & 25.9 & 27.7 & 33.2 & 40.4 & 61.6 & 69.7 & 76.8 & 83.9 & 89.5 & 94.0 \\
\hline & & $4 m s^{-1}$ & 0.0 & 3.7 & 6.3 & 9.4 & 12.1 & 17.5 & 22.0 & 30.6 & 30.6 & 37.7 & 40.6 & 47.1 & 55.2 & 63.3 & 73.0 \\
\hline & & $4.5 m s^{-1}$ & 0.0 & 3.2 & 4.7 & 8.7 & 11.0 & 12.3 & 16.0 & 26.5 & 25.0 & 39.1 & 41.2 & 44.0 & 46.0 & 49.6 & 57.4 \\
\hline
\end{tabular}




\section{APPENDIX C - EXPERIMENTAL WAKE PROFILE PLOTS}

\section{Centreline Profiles}
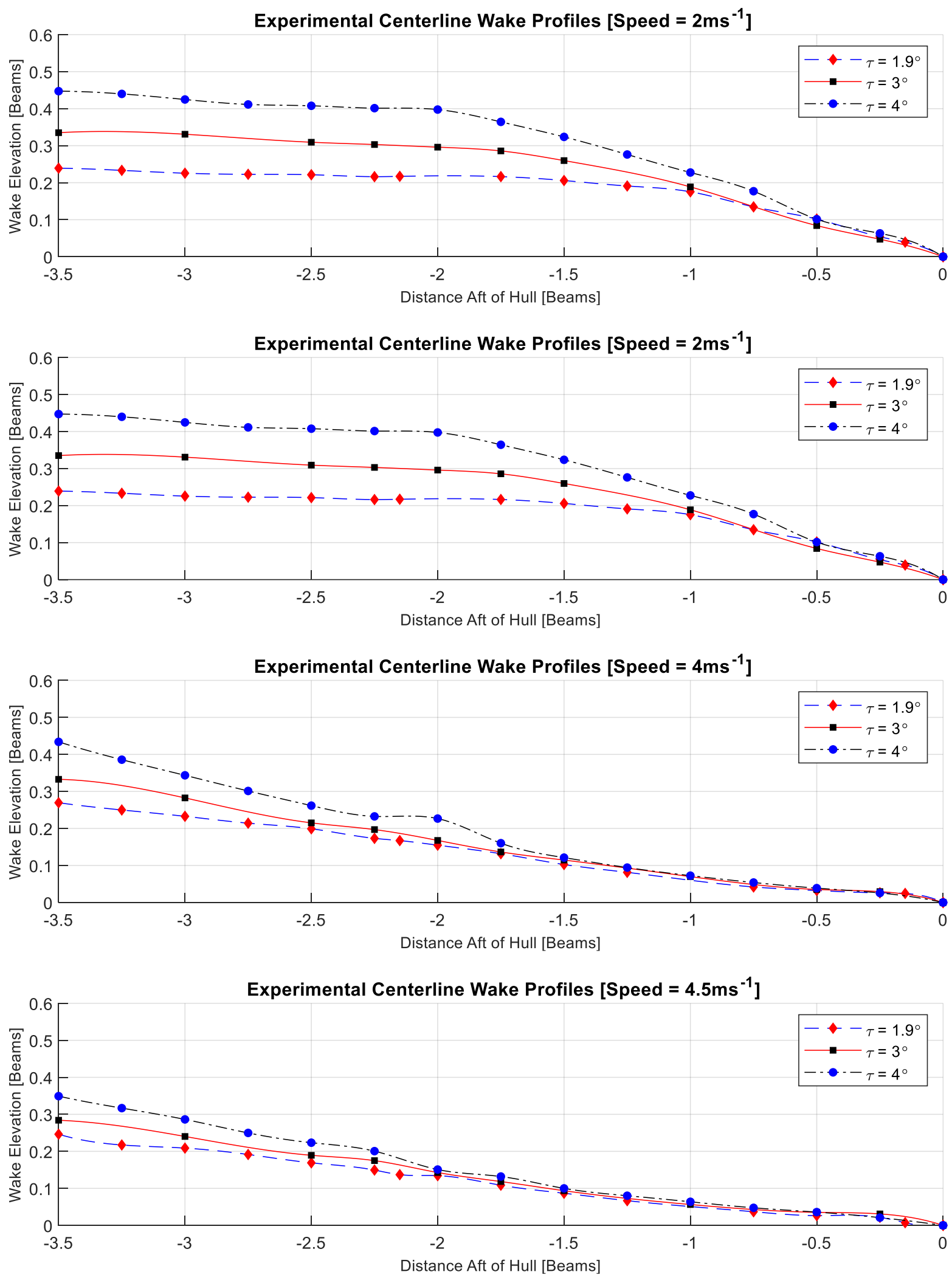

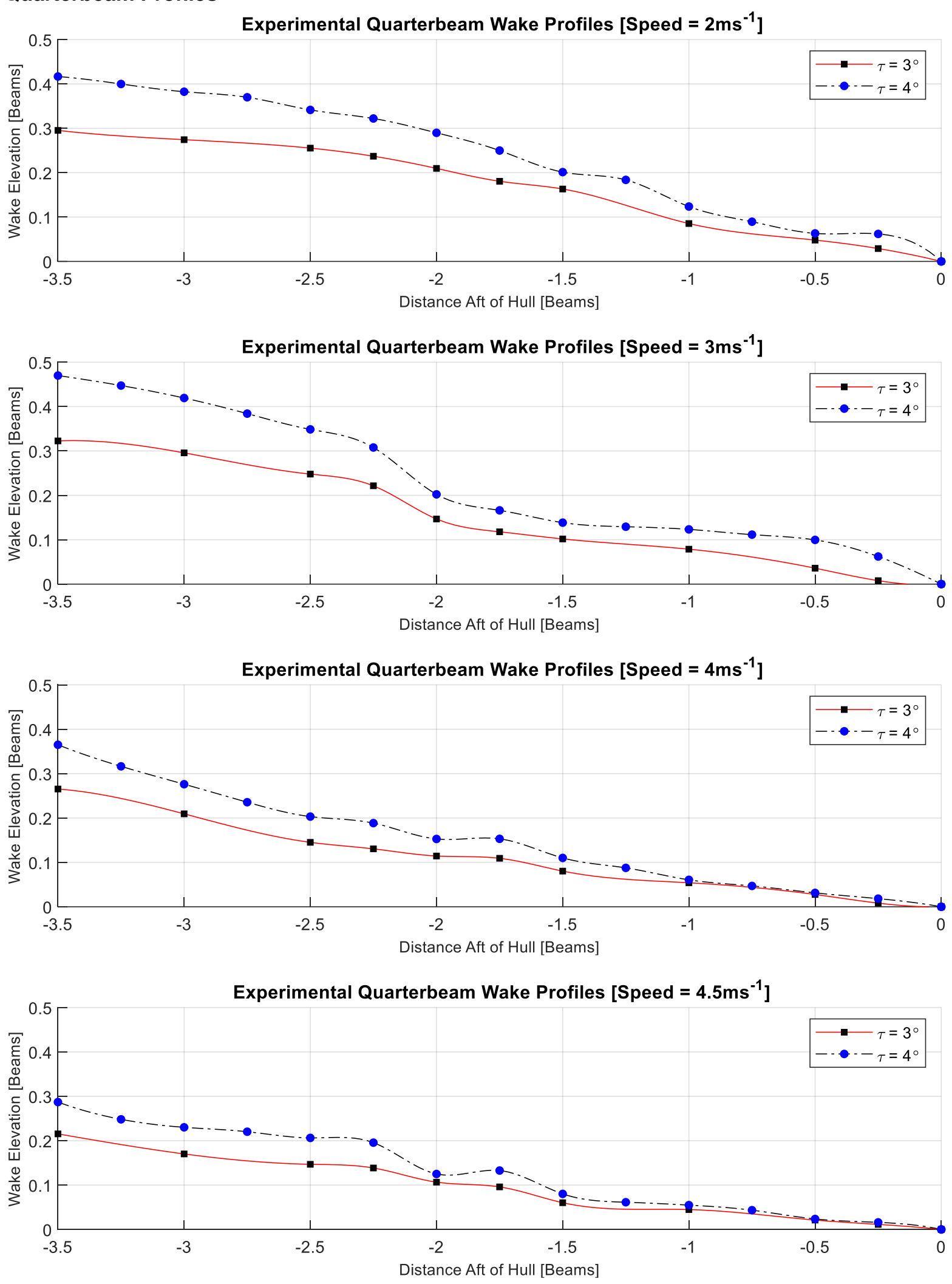
APPENDIX D - WAKE PROFILE RESULTS PLOTS

$2 \mathrm{~ms}^{-1}$ Centreline Profiles
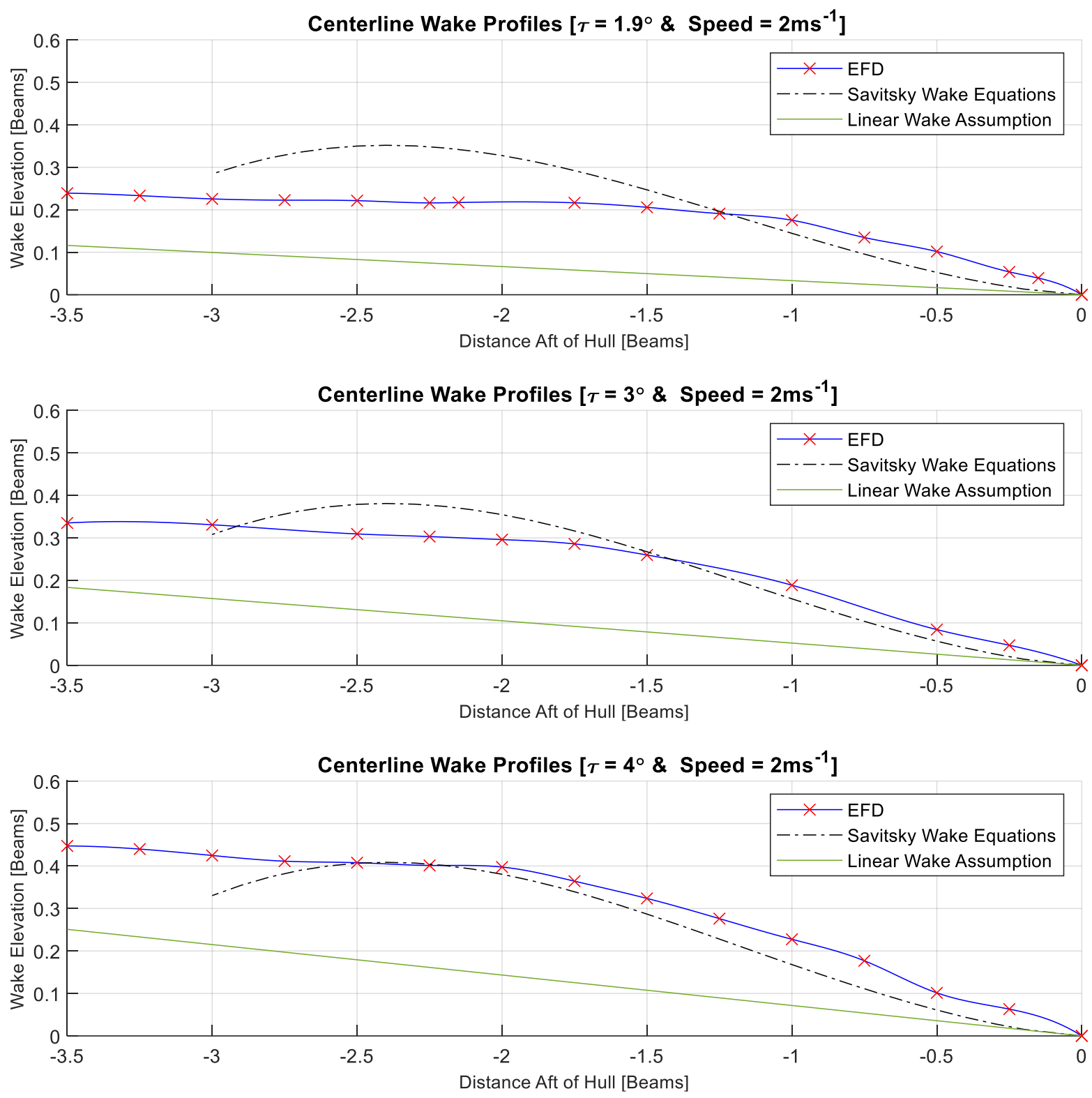

$3 m s^{-1}$ Centreline Profiles

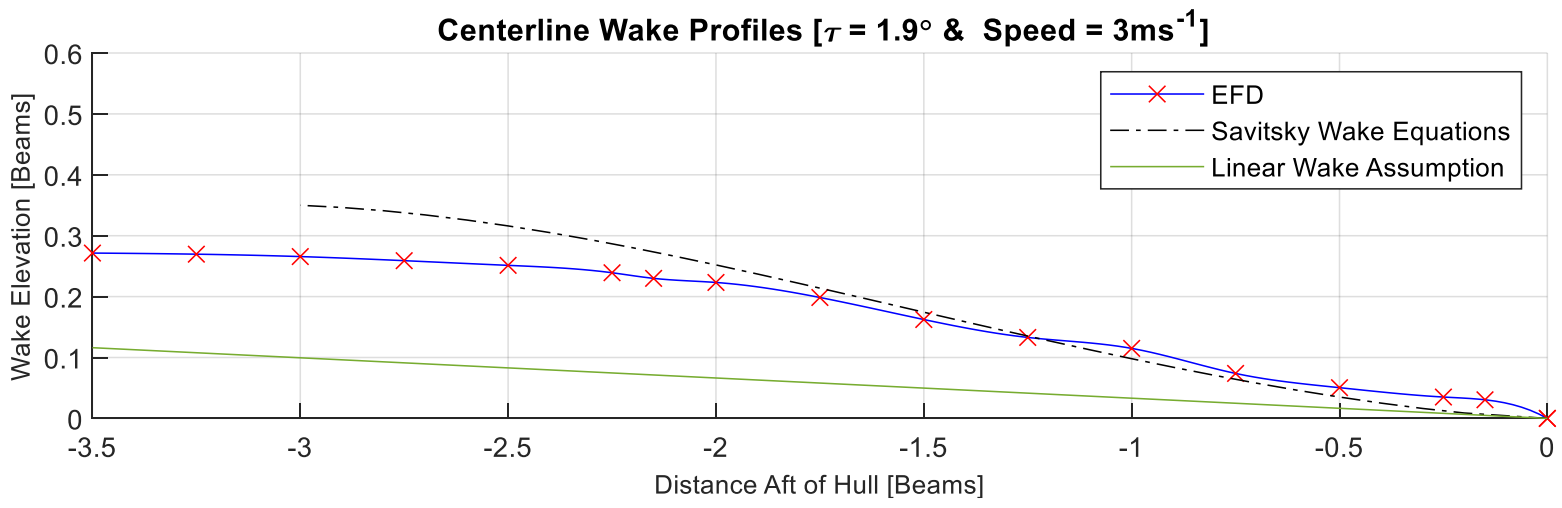



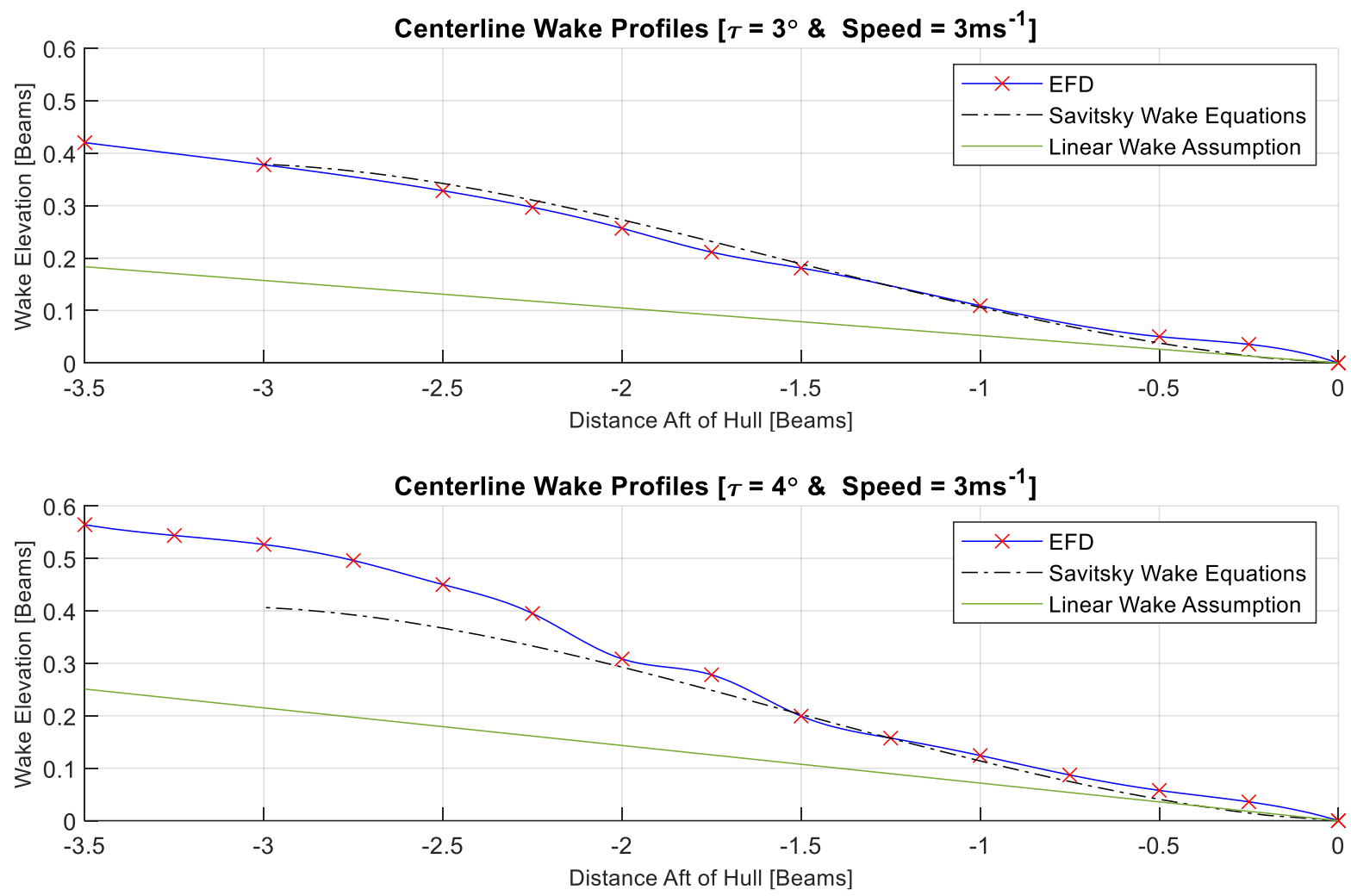

$4 m s^{-1}$ Centreline Profiles
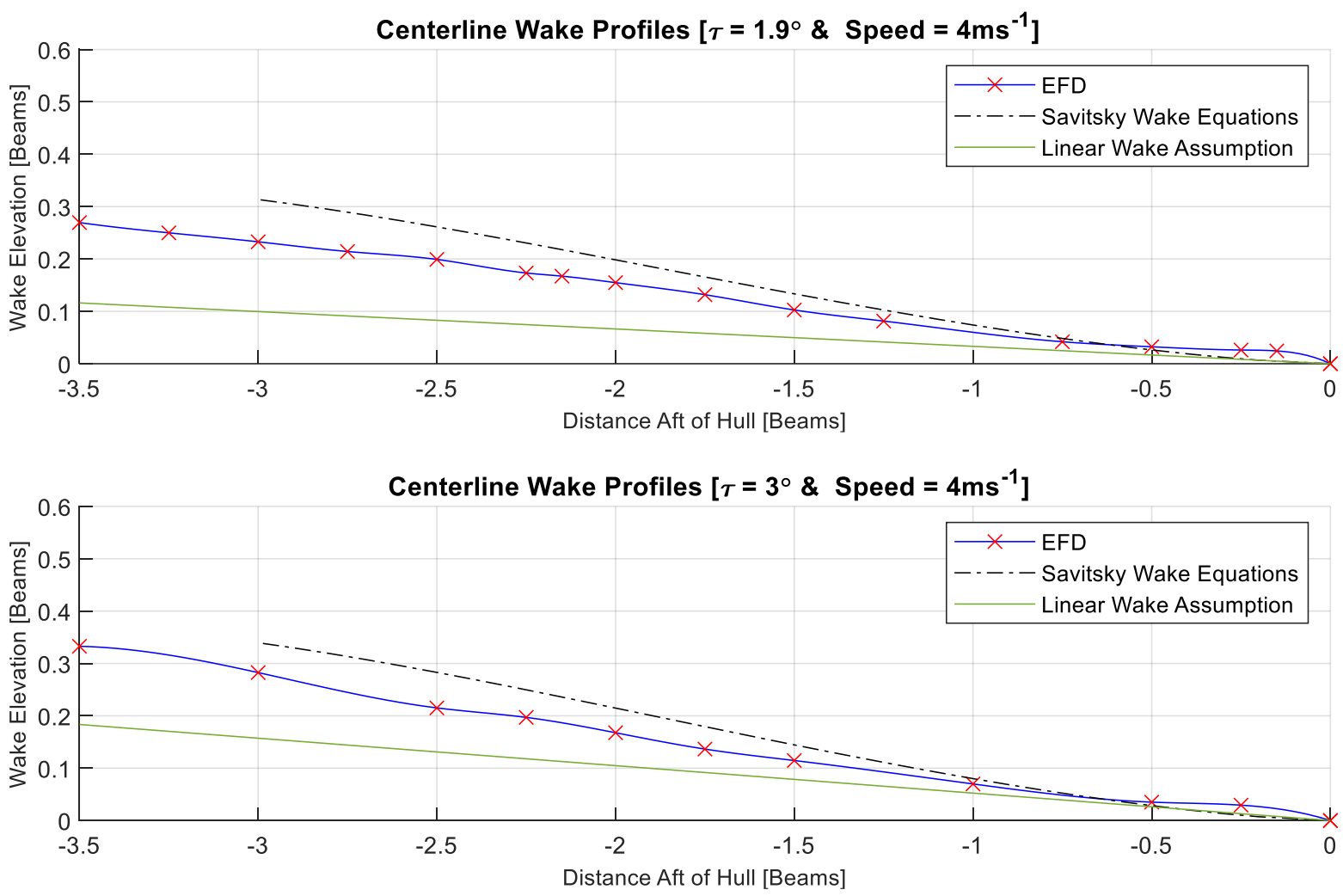


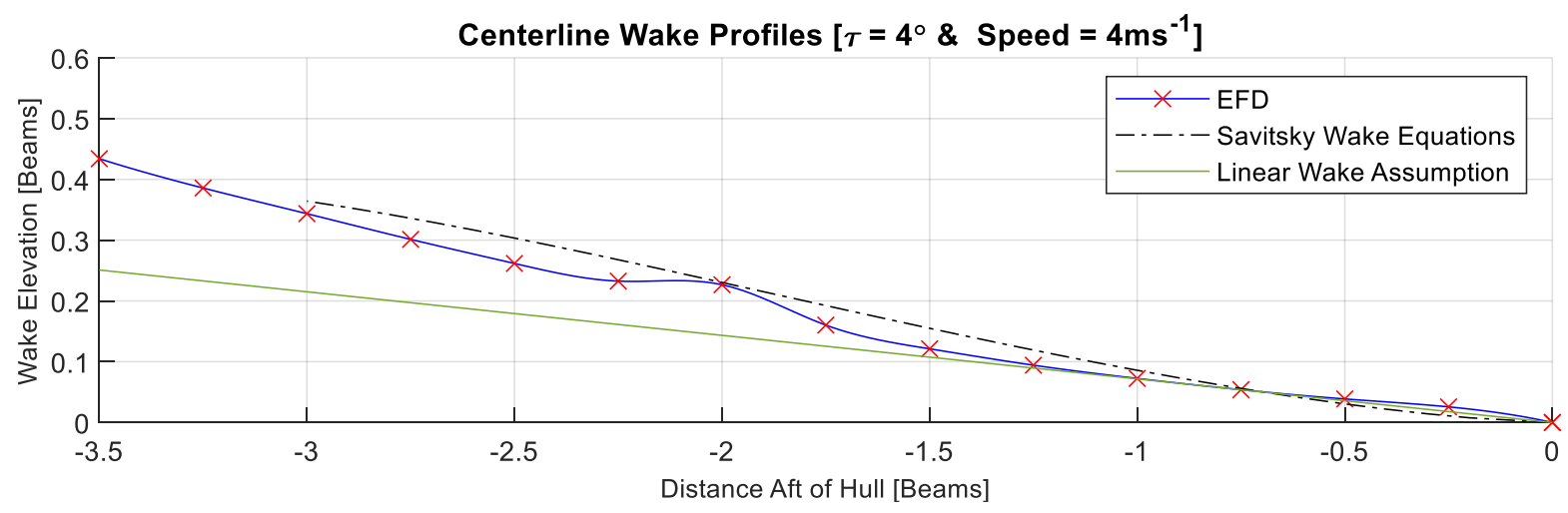

4. $5 m s^{-1}$ Centreline Profiles
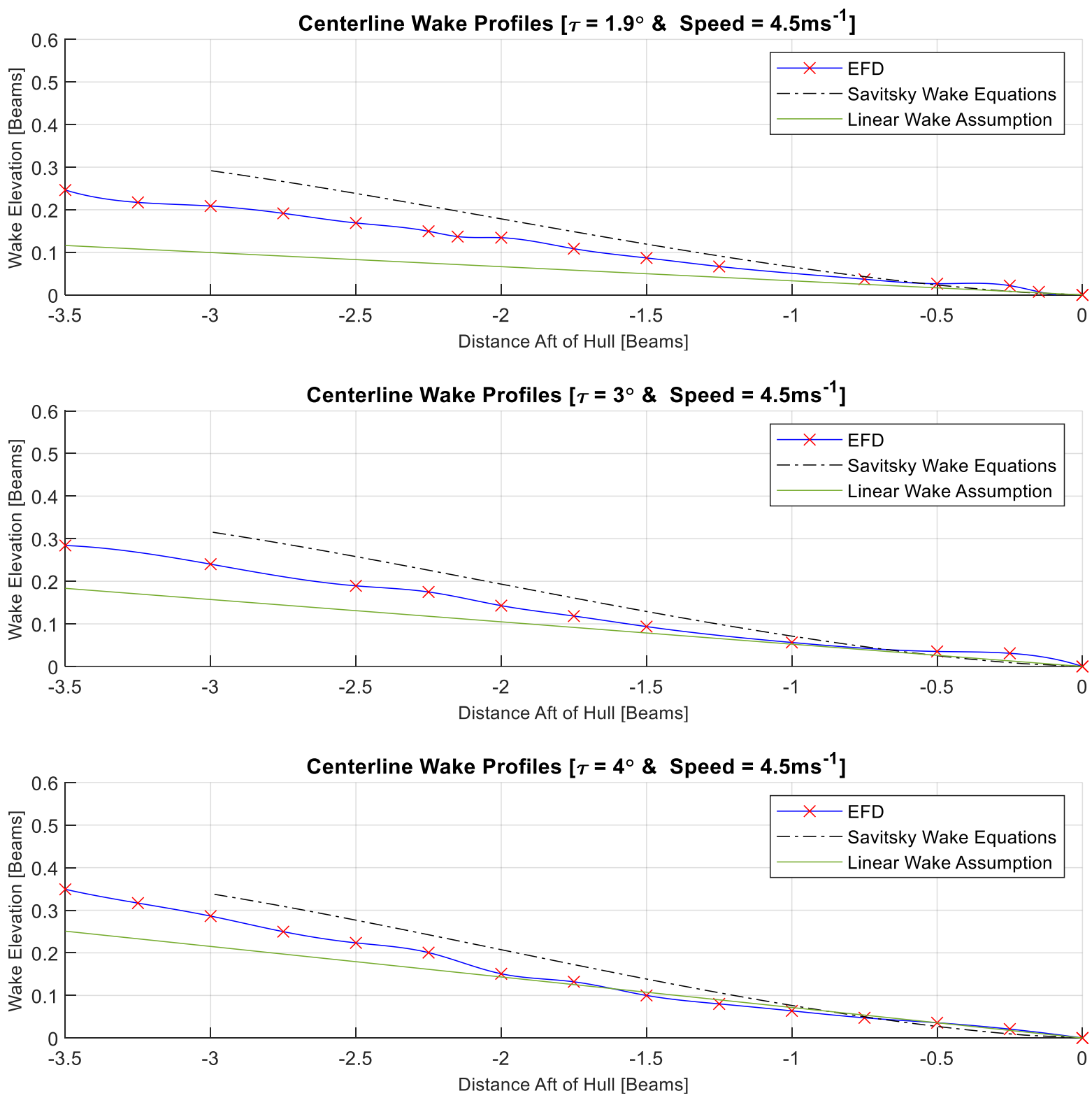


\section{$2 m s^{-1}$ Quarterbeam Profiles}
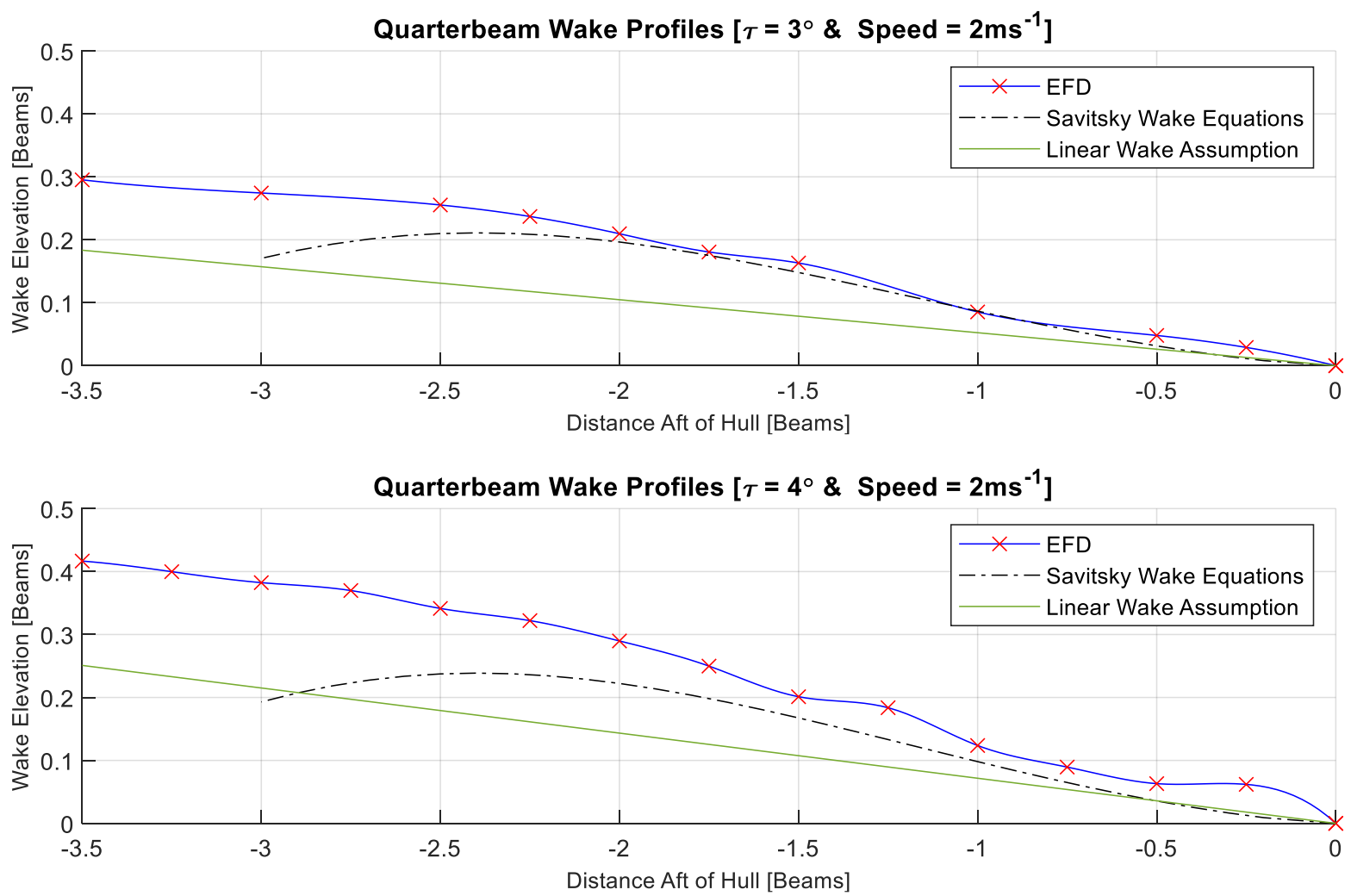

$3 m s^{-1}$ Quarterbeam Profiles
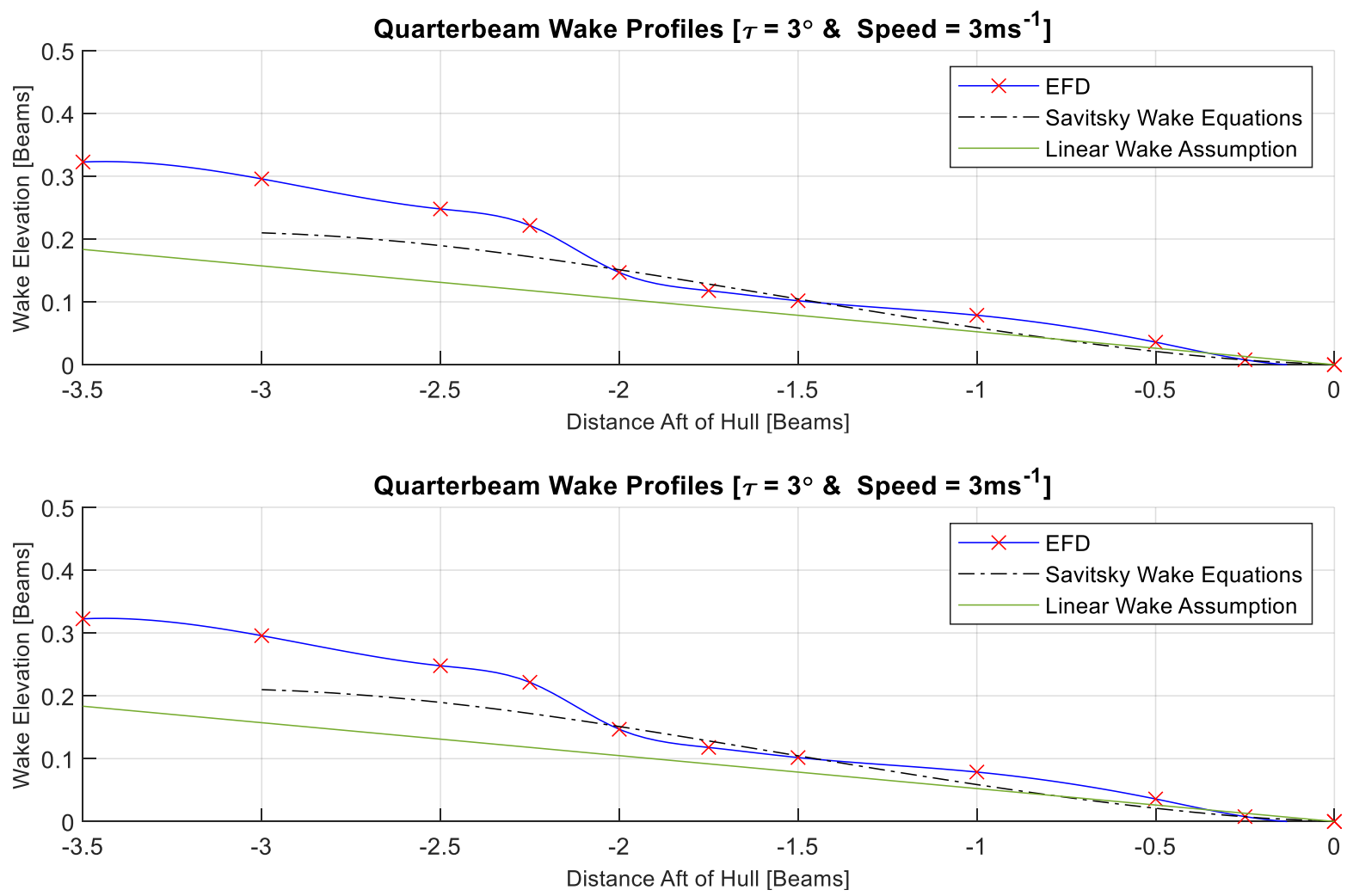
$4 m s^{-1}$ Quarterbeam Profiles
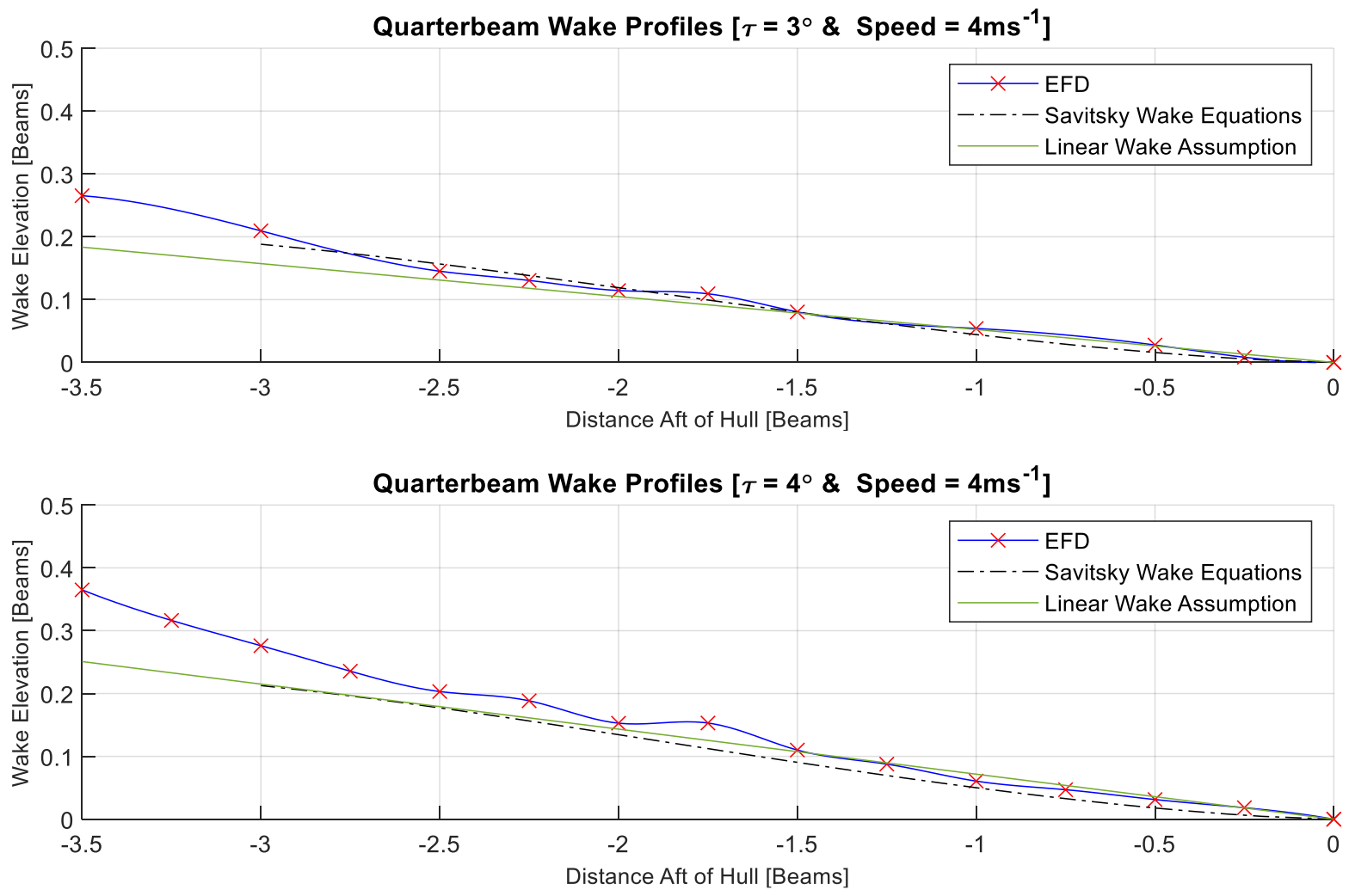

4. $5 \mathrm{~ms}^{-1}$ Quarterbeam Profiles
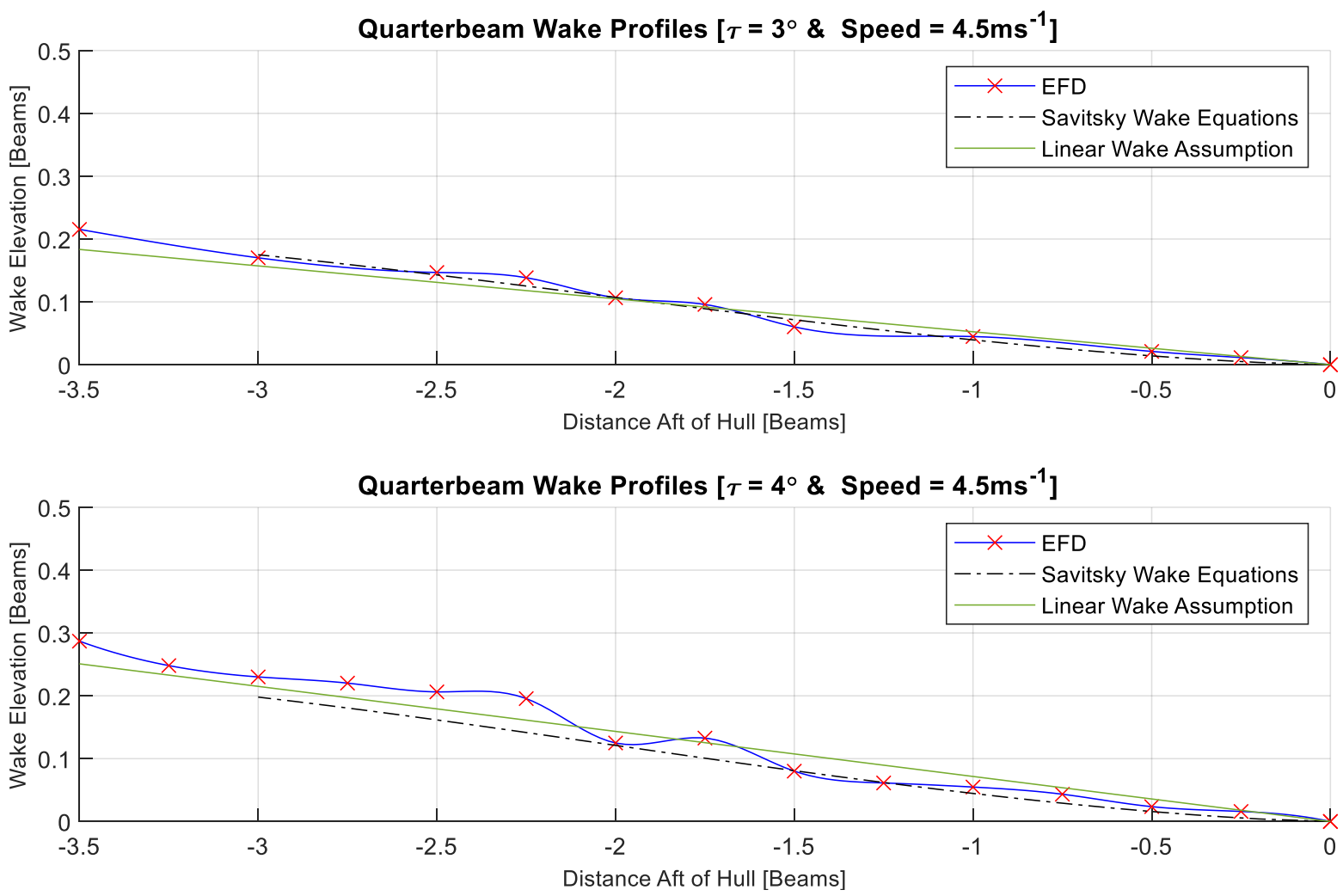